Article

\title{
Air-Traffic Restrictions at the Madeira International Airport Due to Adverse Winds: Links to Synoptic-Scale Patterns and Orographic Effects
}

\author{
Margarida Belo-Pereira ${ }^{1,2, *(\mathbb{D})}$ and João A. Santos ${ }^{2} \mathbb{C}$ \\ 1 Instituto Português do Mar e da Atmosfera, Divisão de Meteorologia Aeronáutica, Rua C do Aeroporto, \\ 1749-077 Lisboa, Portugal \\ 2 Centre for the Research and Technology of Agro-Environmental and Biological Sciences, CITAB, \\ Universidade de Trás-os-Montes e Alto Douro, UTAD, 5000-801 Vila Real, Portugal; jsantos@utad.pt \\ * Correspondence: margarida.belo@ipma.pt
}

Received: 26 September 2020; Accepted: 19 November 2020; Published: 22 November 2020

\begin{abstract}
The Madeira International Airport (MIA) lies on the island's south-eastern coast and it is known to be exposed to wind hazards. A link between these adverse winds at MIA and the synoptic-scale circulation is established using a weather type (WT) classification. From April to September (summer period), five WTs prevail, cumulatively representing nearly $70 \%$ of days. These WTs reflect the presence of well-established Azores high, with some variations on location and strength. Although with a low frequency of occurrence $(<5 \%)$, this anticyclone occasionally strengthens and extends towards Iberia, inducing anomalously strong NNE/NE up to 3-5 km over Madeira. The most severe and longer-lasting wind conditions at the MIA, with a higher frequency of gusts above $35 \mathrm{kt}$, are driven by this synoptic-scale pattern and are more common in summer. An episode of adverse winds at the MIA is analysed, illustrating the occurrence of upstream stagnation, flow splitting, and lee wake formation. The upstream conditions include a low-level inversion, strong NNE/NE winds near and above the inversion and a Froude number less than 1 . The AROME (Application of Research to Operations at Mesoscale) model predicted the occurrence of downslope winds, in association with a large-amplitude mountain wave. At this time, the strongest wind gusts were registered and one aircraft executed a missed approach. The wind regime in different places of the island suggests that these conditions are relatively frequent, mostly in summer. Finally, objective verification of AROME wind forecast, for a three-year period and from June to August, is discussed.
\end{abstract}

Keywords: aircraft operations restrictions; severe winds; weather types; AROME model; Madeira wake; Froude number

\section{Introduction}

In the period from 1967 to 2010, weather was the primary cause of the growing percentage of annual aircraft accidents. Most of the accidents attributed to weather conditions occur in latitudes between $12^{\circ}$ and $38^{\circ} \mathrm{N} / \mathrm{S}$ [1]. Moreover, adverse winds and turbulence have had a large contribution to aviation weather-related accidents [2]. Previous studies have shown that mountain wave mechanisms are an important source of turbulence, contributing to numerous aircraft incidents and accidents. For instance, mountain waves have been associated with extreme clear-air turbulence at cruise levels, causing severe structural damages to aircraft [3] or leading to several seriously injured passengers [4]. In the lower troposphere (below $3 \mathrm{~km}$ ), mountain wave turbulence can be particularly hazardous and was the probable cause of a fatal light aircraft crash on 31 July 2007 in Australia [5]. On 18 November 
2008, a commercial aircraft experienced severe turbulence when descending over the south-eastern coast of Iceland. This incident was associated with a large amplitude lee wave that caused an atmospheric rotor and strong downslope winds [6]. On 20 December 2008, during the take-off phase at the Denver International Airport, a Boeing 737 deviated off the side of the runway due to severe crosswinds (approximately $37 \mathrm{kt}$ ) caused by lee waves (Keller et al. [7]). Mountain waves were also the probable cause of a hard landing event in the Pico (Azores) aerodrome (Maruhashi et al. [8]).

Several studies have characterized the flow response to an isolated circular mountain in terms of dimensionless numbers, such as the Froude number, $\mathrm{Fr}=\mathrm{U} / \mathrm{Nh}_{\mathrm{m}}$ [9-12], where $\mathrm{N}$ is the Brunt-Väisälä frequency, $h_{m}$ the mountain height and $U$ the upstream wind speed. Other studies have considered the inverse of $\mathrm{Fr}$, also known as non-dimensional mountain height, $\mathrm{M}[13,14]$. These studies showed that for $\mathrm{Fr}<<1(\mathrm{M}>>1)$ upstream stagnation and flow splitting occurs and a wake may form leeward of the obstacle. Upstream stagnation is defined as an abrupt slowing of the airflow on the windward side of a mountain. Flow stagnation occurs due to the positive upstream pressure anomaly associated with the disturbance and occurs at height zs on the upstream slope. Below zs, the flow splits and circumvents the obstacle rather than flowing over it, while above zs the flow surpasses the obstacle, phenomena known as flow splitting [14]. The wake region can be identified by a flow deceleration or by the presence of vortices (Smith [15]). These vortices can have either a quasi-steady nature $[9,16]$ or an unstable pattern, in which vortices of alternating signs are periodically shed downstream to form a Kármán vortex street [17-19]. Schär and Smith [10] showed that wake vortices could form in association with hydraulic jumps, when the upstream Froude number is below 1 and the inversion layer lies at or below the mountain top. Other studies $[11,13]$ suggested that for a low Froude number, lee vortex formation might be associated with wave breaking (breakdown of laminar flow). Moreover, the occurrence of wave breaking is more probable for wider (elliptic) mountains [14,20]. Wave breaking has a turbulent nature and may produce downslope windstorms $[3,20]$, which can be hazardous to aviation. Therefore, it is very important to predict the favourable conditions for their occurrence.

The Madeira archipelago is located in the subtropical eastern North Atlantic, lying between the $32.4^{\circ} \mathrm{N}$ and $33.2^{\circ} \mathrm{N}$ parallels and centred along the $16.8^{\circ} \mathrm{W}$ meridian (Figure 1). The island of Madeira, the largest of the archipelago, has a ca. $54 \mathrm{~km}$ mountain range, WNW-ESE oriented, with an NNE-SSW length of ca. $22 \mathrm{~km}$. The island has a complex terrain, rising steeply from the coast and peaking at an altitude of $1862 \mathrm{~m}$ (Pico Ruivo).

The weather in Madeira is strongly influenced by the position and strength of the semi-permanent subtropical anticyclone over the North Atlantic (known as the Azores high). Spring sets the beginning of the rapid expansion, strengthening, and northward migration of the Azores high, which continues until summer (Davis et al. [21]). This intensification leads to the reinforcement of the subsidence in the Macaronesia region, contributing to the strengthening of the inversion layer and to the lowering of its base height during these months [22]. Due to this fact, at Funchal (main city in Madeira), the inversion layer is frequently below the height of the Madeira mountain range (Grubišić, et al. [23]). Furthermore, from April to August, the predominant incoming flow to Madeira is from North to Northeast, driven by the eastern branch of the Azores high. Therefore, Madeira Island is frequently oriented nearly perpendicular to the incoming airflow. The combination of the aforementioned conditions is indeed prone to wake formation [23].

The Madeira International Airport (MIA) lies on the island's south-eastern coast and, due to its location, is often affected by turbulence associated with the island wake. For instance, during the first 100 days of 2018, approximately $130 \mathrm{~h}, 550$ aircraft movements and 80,000 passengers were affected, due to adverse wind conditions. Since tourism is the main Madeira's economic activity and the bulk of tourists visiting Madeira arrive through the airport, these air-traffic restrictions have a large negative impact on the island's economy. 

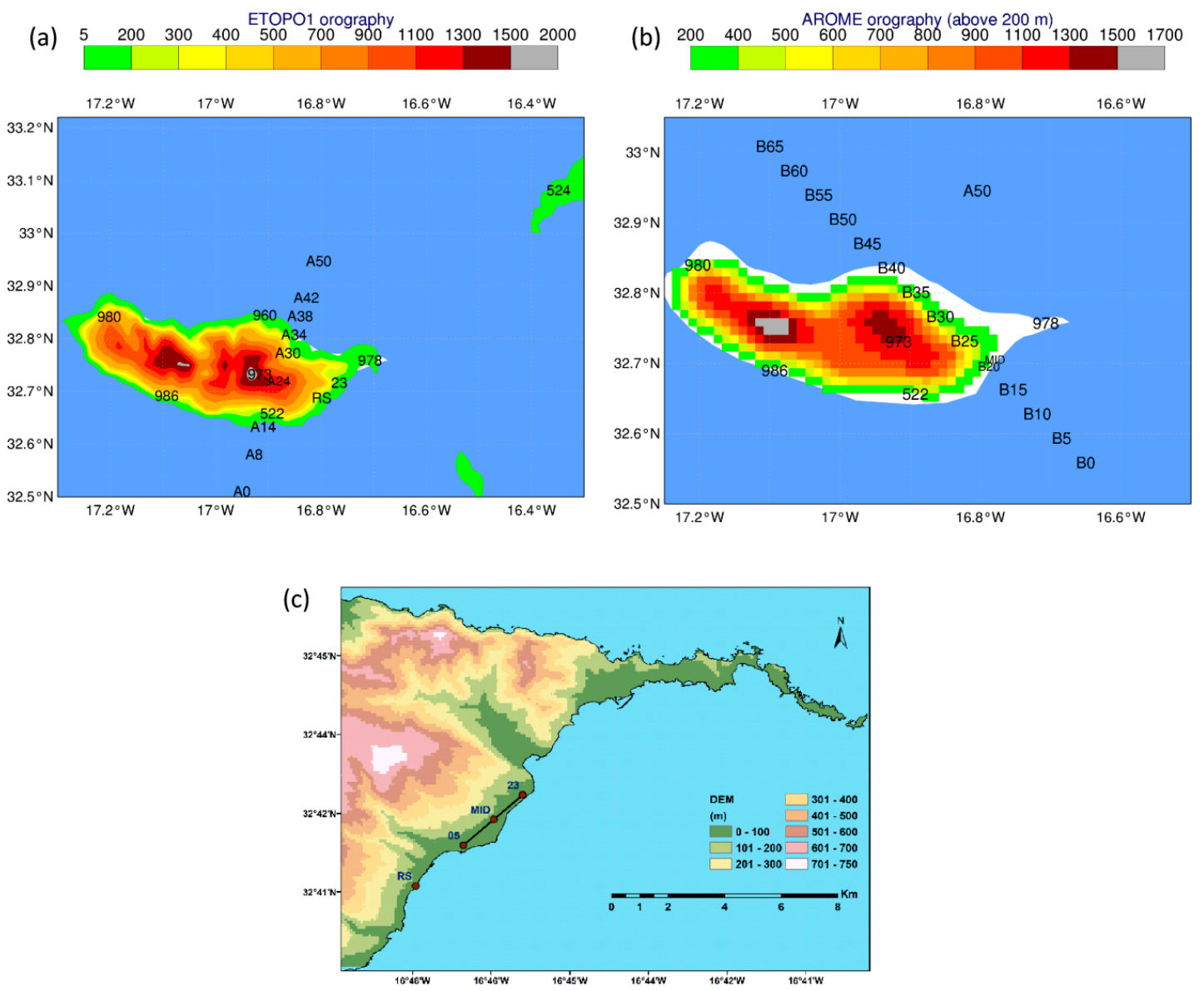

Figure 1. Hypsometric maps of the Madeira Island using the (a) ETOPO1 and (b) Application of Research to Operations at Mesoscale (AROME) orography. (c) Location of the CR Airport (solid black line) and the sites RS, 05, MID and 23, along with hypsometry from a digital elevation model (DEM) with 90 m spatial resolution (SRTM 90 m Digital Elevation Database v4.1).

The Madeira atmospheric wake has been previously documented [23-25]. However, to the authors' best knowledge, the impact of this wake to the airport operations has not been addressed. Besides, the link between synoptic-scale weather patterns and wind regimes at Madeira Island and, in particular at the MIA, was poorly addressed. At the Portuguese Weather Service (Portuguese Institute for Sea and Atmosphere, IPMA, Lisbon, Portugal), the Application of Research to Operations at Mesoscale (AROME) model is routinely used by forecasters. Therefore, the assessment of the performance of AROME wind forecasts is of great importance.

This study has four goals. The first is to diagnose the take-off and landing restrictions at Madeira airport due to wind limitations. The second is to identify relationships between these operating limitations and synoptic-scale regimes. The third objective is to illustrate the interaction between the synoptic-scale forcing and the orographic effects during one particular event of adverse winds at the MIA (case study). The final goal is to assess the agreement between AROME forecasts and observations of wind at $10 \mathrm{~m}$-height on the Madeira island, primarily at the MIA.

The remainder of this paper is organized as follows. A brief description of the observations, the AROME model and the weather type methodology is presented in Section 2. The wind regime in Madeira Island, the temporal variability of the take-off and landing restrictions at Madeira airport due to adverse winds, as well as its connection with weather types, is analysed in Section 3. An episode of adverse winds at the MIA is analysed in Section 3.3. The objective verification of wind forecasts of the AROME model is also presented in Section 3.4. Finally, the summary and conclusions are drawn in Section 4. 


\section{Data and Methods}

\subsection{Observations}

The hypsometric maps of Madeira Island using both the ETOPO1 and AROME orography are displayed in Figure 1. The geographical location of the MIA is also shown in Figure 1c, along with the orography from the SRTM 90m Digital Elevation Database v4.1. The MIA is aligned in the southwest-northeast direction, nearly parallel to the coastline with steep slopes (part of one runway is already over the sea). The wind observations at the MIA are provided by the Väisälä Wind Set WA15, which consists of a Väisälä Anemometer WAA151 and a Väisälä Wind Vane WAV151. This system is also installed at Rosário (RS) and three sites of the airport (RWY05, MID, RWY23). Their location is shown in Figure 1c. At these sites, the average 2- and 10-min winds are stored. At the other locations, only the average 10-min wind is recorded. Wind gust is defined as a three-second average.

\subsection{Weather Typing and Reanalysis Data}

A weather typing approach was applied to assemble similar daily synoptic conditions in the eastern North Atlantic and adjacent landmasses, particularly in the area surrounding the Madeira Island. The resulting groups are henceforth called weather types (WT). As such, the following geographical sector was selected: $30^{\circ} \mathrm{W}-10^{\circ} \mathrm{E} ; 20-60^{\circ} \mathrm{N}$. A sensitivity analysis on the border limits showed no significant changes in the results when the geographical limits are changed up to $10^{\circ}$ in either latitude or longitude. However, a relatively large area provides a larger sample of data, increasing the robustness of the identified WTs, also enabling their application in future studies devoted to both operational numerical weather prediction and climate change projections.

A k-means analysis was carried out on the leading principal components of mean sea level pressure (MSLP) and $700 \mathrm{hPa}$ geopotential height (Z700) at $12 \mathrm{UTC}$. The use of Z700 enhanced the vertical coherency in each WT dynamical structure, from the surface to nearly $3 \mathrm{~km}$, which is particularly important when analysing the interplay between large-scale flow and the Madeira's orographic barriers. A similar multi-variable methodology was previously applied [26]. Both MSLP and Z700 were retrieved from the ERA5 reanalysis dataset and for the period from 2010 to 2018 . The ERA5 Z700 at 12 UTC was also used in the calculation of composite patterns. Data are available on a regular grid of $0.25^{\circ}$ longitude $\times 0.25^{\circ}$ latitude (a spatial resolution of approximately $30 \mathrm{~km}$ ) and were provided by the Copernicus Climate Data Store platform. Besides its relatively fine grid resolution, ERA5 reanalysis comprises important improvements when compared to preceding reanalysis products, such as ERA-Interim [27].

A preliminary analysis was carried out to assess the sensitivity of the results to the number of WTs. The association between air traffic restrictions at MIA and WTs is clearer when considering twenty or more WTs. Therefore, twenty were selected as a trade-off between the discriminative power of the WTs and the parsimony in their number. For each grid point, MSLP/Z700 long-term means were computed for each calendar day and were subsequently smoothed out by a low-pass Lanczos filter, with a cut-off period of 30 days. These gridded smoothed seasonal signals were then subtracted from the raw daily MSLP/Z700 fields, thus removing seasonality at each grid point and obtaining the corresponding daily anomalies. Principal component analyses (PCA) were then separately applied to both MSLP and Z700 anomalies. Only the principal components that cumulatively explain ca. 90\% of the total temporal variance of each field were retained. These components were scaled to zero mean and unit variance time series and then subject to k-means clustering. Previous studies stressed that the combination of PCA and k-means increases the robustness of the k-means clustering [28]. For clustering, the squared Euclidean distance was used and a 10\% sub-sample was selected for initial seeding. The clustering was repeated 20 times and the best solution was eventually chosen (a solution that minimizes the intra-cluster variance and maximizes the inter-cluster variance). A final list of days was thereby obtained where each day was keyed to a given WT. The composites (average fields) of the atmospheric variables for all days of a given WT are thereby archetypical spatial patterns of the atmospheric large-scale circulation during that WT. As they are mean fields, daily patterns may have 
significant departures from the mean. Nonetheless, due to the relatively high number of WTs (20) and to the optimization procedure followed in the clustering approach these departures were minimized.

\subsection{AROME Model}

The AROME model is a non-hydrostatic spectral model that uses a semi-implicit semi-Lagrangian (SISL) scheme, as described by Seity et al. [29]. The representation of turbulence in the planetary boundary layer (PBL) is based on a prognostic Turbulent Kinetic Energy (TKE) equation, combined with a diagnostic mixing length [30]. The wind gust depends on the wind speed and TKE at $10 \mathrm{~m}$, as explained by Amodei et al. [31]. AROME orography is extracted from the Global 30 Arc-Second Elevation Data Set (GTOPO30) database (averaged at a $0.0025^{\circ}$ resolution). However, the mean orography is smoothed using a 16th-order diffusion operator. Thus, the smoothed grid-scale surface elevation represents scales greater than the model's nominal horizontal resolution. At IPMA, AROME runs operationally, four times a day, with a horizontal grid spacing of $2.5 \mathrm{~km}$ and 60 vertical levels. Its initial and boundary conditions emanate from the ARPEGE (Action de Recherche Petite Échelle Grande Échelle) model.

\section{Results and Discussion}

\subsection{Wind Regime at Madeira Island}

In order to characterize the climatological conditions of the large-scale atmospheric flow in the eastern North Atlantic, with particular emphasis on the area of the Madeira Archipelago, the mean patterns of both MSLP and Z700 are depicted in Figure 2. To take into account seasonality, these patterns are shown for the wintertime (winter half of the year, October-March) and summertime (summer half of the year, April-September) periods. The prominence of the Azores high is apparent throughout the year. Nevertheless, the expansion and north-eastward migration of the Azores high during summer in comparison to winter is clear (Figure 2a,b). Further, near-surface low-pressure areas are patent over North Africa in summer, thus strengthening the MSLP gradient between Madeira and North Africa. A small inflection in the isobaric line crossing the Madeira Island is also noteworthy, highlighting that mesoscale effects induced by the island orography are to some extent captured by ERA5. A trough at Z700 over Madeira and Canary archipelagos is also visible during summer. In winter, a ridge at Z700 is visible over the Azores high and a strong meridional (north-south) gradient is noticeable at higher latitudes, consistently with the westerlies.

At Porto Santo (station 524), in winter, the large variability of the wind direction is noticeable (Figure 2c), with a small prevalence of NNW wind (nearly 9\%). On the other hand, in summer, there is a large predominance of northerly (30\%) and north-northeasterly $(20 \%)$ winds (Figure $2 \mathrm{~d}$ ). This is consistent with fact that Madeira Island is located along the south-eastern flank of the Azores high, which is noticeably more prevalent in summer, while in winter a large variability of weather regimes occurs, as it will be shown in the next subsection.

The prevailing summer large-scale N/NE winds (depicted at Porto Santo) over the Madeira Island are modified by the complex topography of the island. At the northern central part of the island (station 960), the wind is often below $15 \mathrm{kt}\left(<7.5 \mathrm{~m} \mathrm{~s}^{-1}\right.$ ). At Pico Ruivo (station 973), however, NE winds are predominant, with intensity ranging between 15 to $25 \mathrm{kt}$ nearly $14 \%$ of the time (Figure 3 ). On the northwestern part of the island (Station 980), northeasterly and easterly winds are dominant, with gusts above $30 \mathrm{kt}$ near $20 \%$ of the time and average 10-min wind above $25 \mathrm{kt}$ almost $15 \%$ of the time. At Ponta de São Lourenço (station 978), the NW and NNW winds prevail, with gusts above $30 \mathrm{kt}$ nearly $4 \%$ of the time and average 10 -min wind exceeding $20 \mathrm{kt}$ about $5 \%$ of the time (Figure 3 and Figure S1). In Funchal, the average 10-min wind is less than $5 \mathrm{kt} 92 \%$ of the time (not shown). At RWY05, the NE and NNE winds prevail. At this location, gusts above $25 \mathrm{kt}$ occur nearly $9 \%$ of the time, mostly in association with the prevailing wind directions. The observed variations in the wind regimes of different locations in the Madeira Island are related to the occurrence of upstream stagnation, flow splitting and lee wake development $[13,14,23]$. During wintertime, the frequency of 
SW winds increases in the western and eastern regions of Madeira (Figure S2), in association with an increase in the frequency of the cyclonic regimes, as will be corroborated.

Figure 4 shows the wind roses for average 2-min wind for Rosario (RS) and three locations at the MIA (RWY05, MID and RWY23) during summertime, illustrating relevant differences between nearby locations (see Figure 1c). At the RS site, the wind prevails from NNW to NE, with maximum values ranging between 20 to $25 \mathrm{kt}$ about $2 \%$ of the time. At this site, gusts above $30 \mathrm{kt}$ are more frequent for NNW winds, but can also occur for NE winds (Figure S3). Despite some differences, all three sites of the airport exhibit a strong preponderance of N/NE winds, which are also responsible for the vast majority of wind gusts above $30 \mathrm{kt}$. NNE and NE winds prevail at RWY05, NNE and $\mathrm{N}$ at MID, and N at RWY23. The frequency of weak winds (below $5 \mathrm{kt}$ ) is higher at RS and RWY05 (nearly $21 \%$ of occurrence) than in the other sites of the airport. This reflects the influence of the Island wake, as it will be illustrated in a case study analysis. In winter, there is a preponderance of N/NE winds, but with a lower frequency than in summer (see also Figures S4 and S5). Moreover, in winter, SW winds have a frequency of occurrence of $16 \%$ and are responsible for gusts above $25 \mathrm{kt}$ in $4-5 \%$ of the times (Figure S4).

(a)

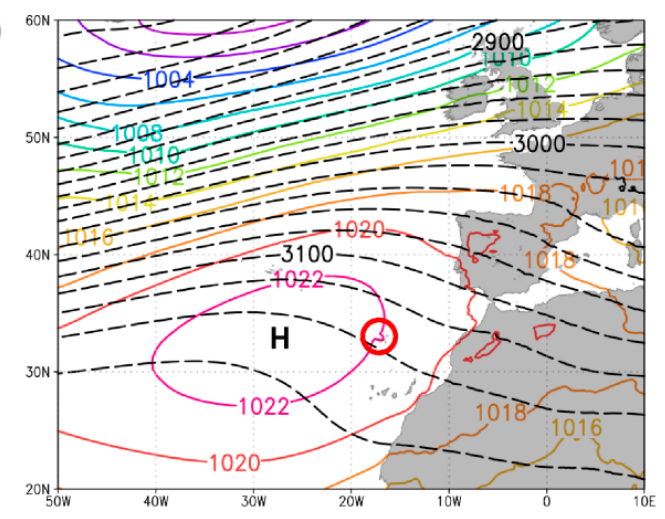

(c)

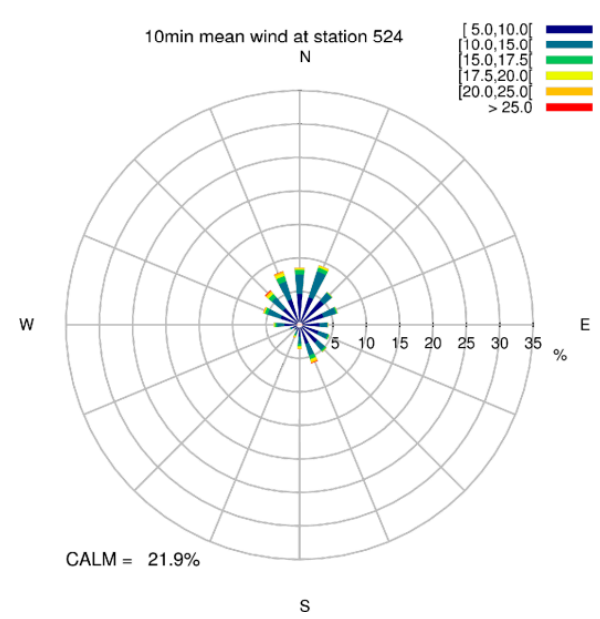

(b)

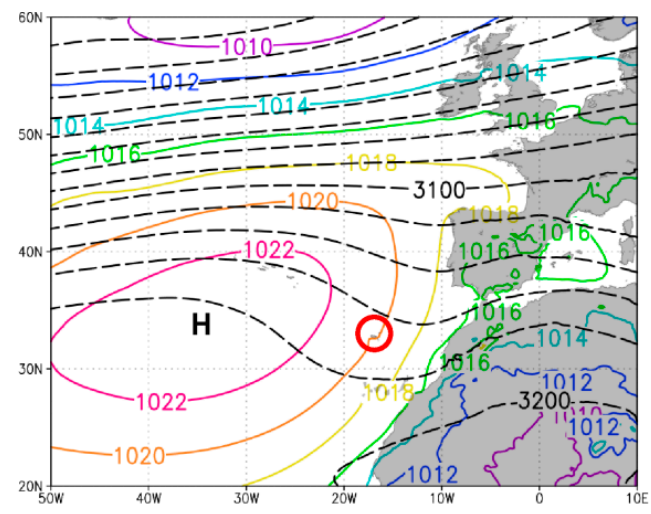

(d)

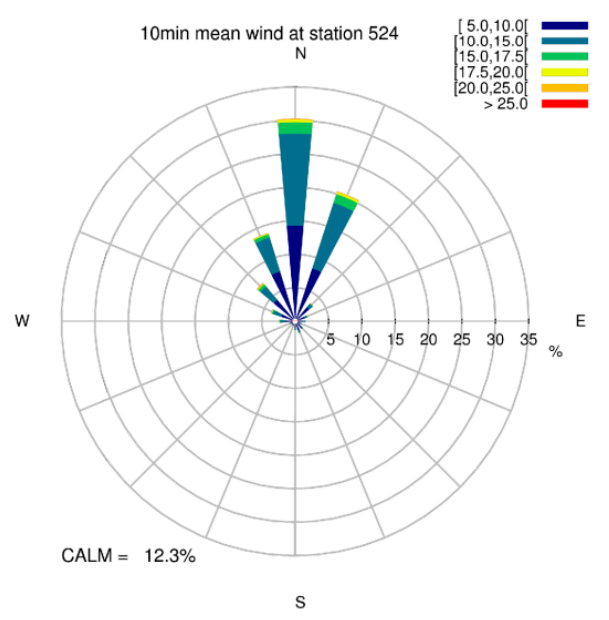

Figure 2. Composites of the daily mean sea level pressure (solid contours) and $700 \mathrm{hPa}$ geopotential height (dashed contours) for (a) winter (October-March) and (b) summer (April-September) over the eastern North Atlantic and adjacent landmasses (grey shaded). The red circle indicates the location of Madeira Island. Wind roses screening the relative frequencies of occurrence (in percentage) of the average 10-min wind at 10-m height (in kt, $\sim 0.51 \mathrm{~ms}^{-1}$ ) in winter (c) and summer (d) at Porto Santo (station 524, see location in Figure 1a). 

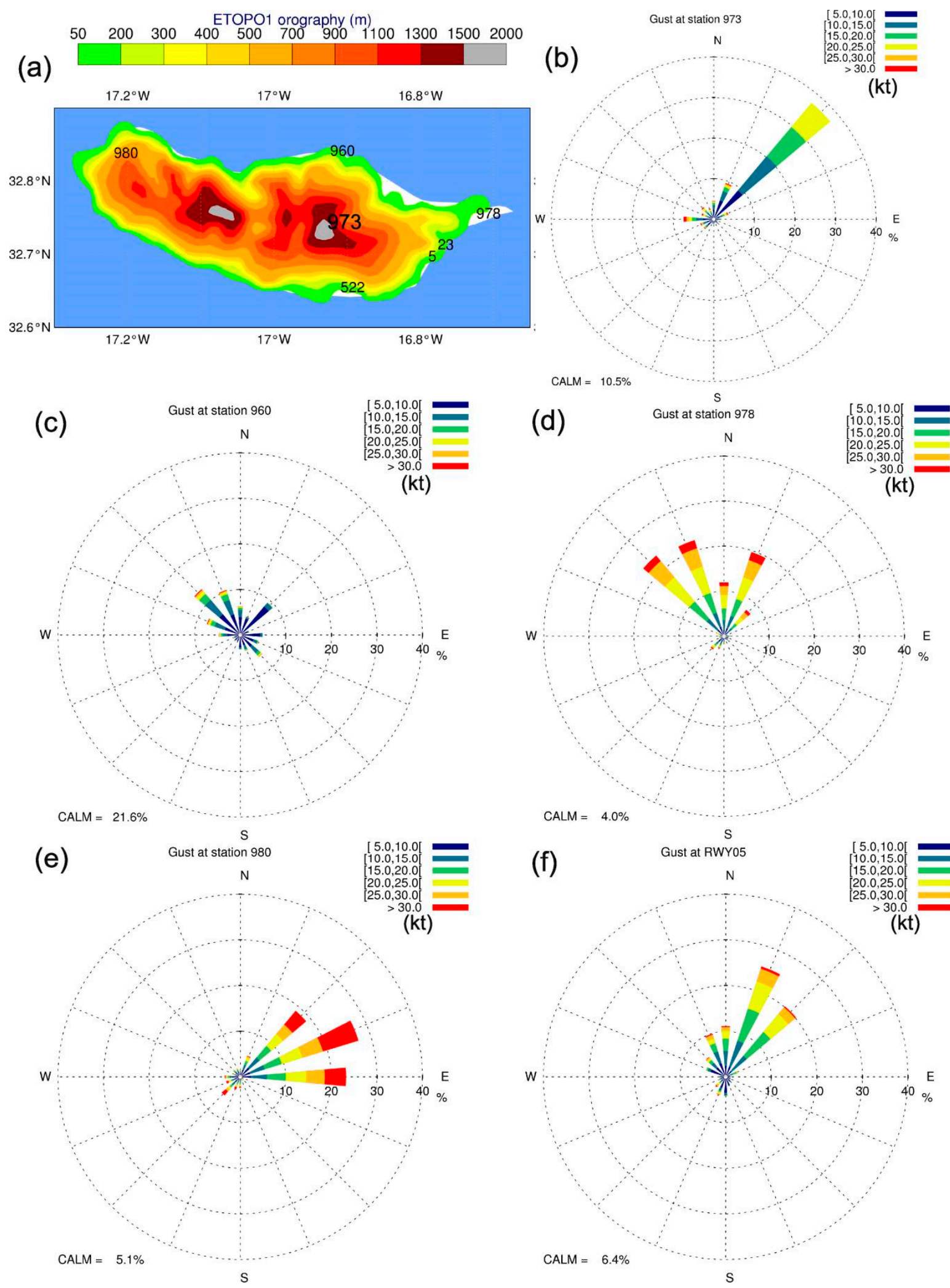

Figure 3. (a) Hypsometric chart of Madeira Island based on ETOPO1 orography (elevation in m). (b-f) Wind roses screening the relative frequencies of occurrence (in percent) of the wind gusts (in kt) in the extended summer period (April-September) and at the outlined locations of Madeira Island ((b): Station 973, (c): Station 960, (d): Station 978, (e): Station 980, (f): RWY05). 

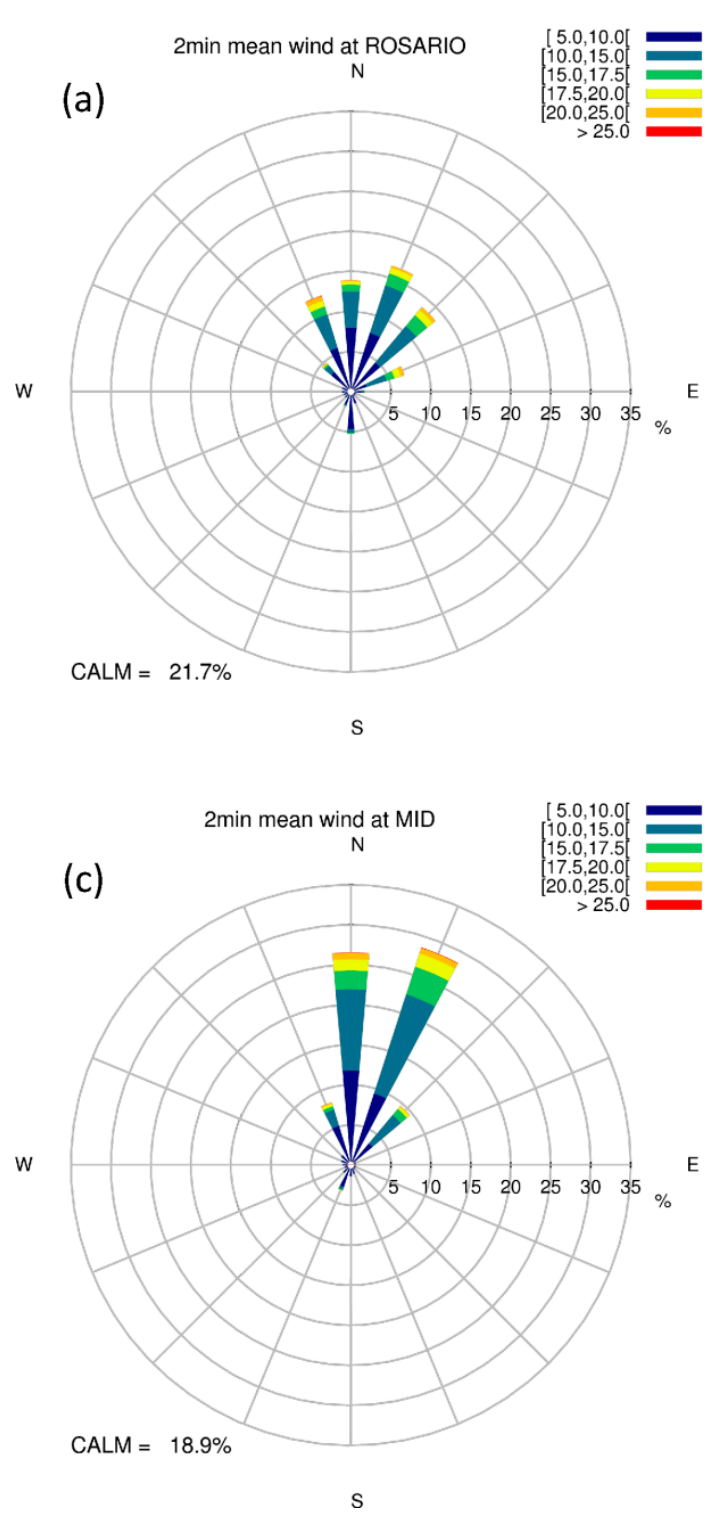
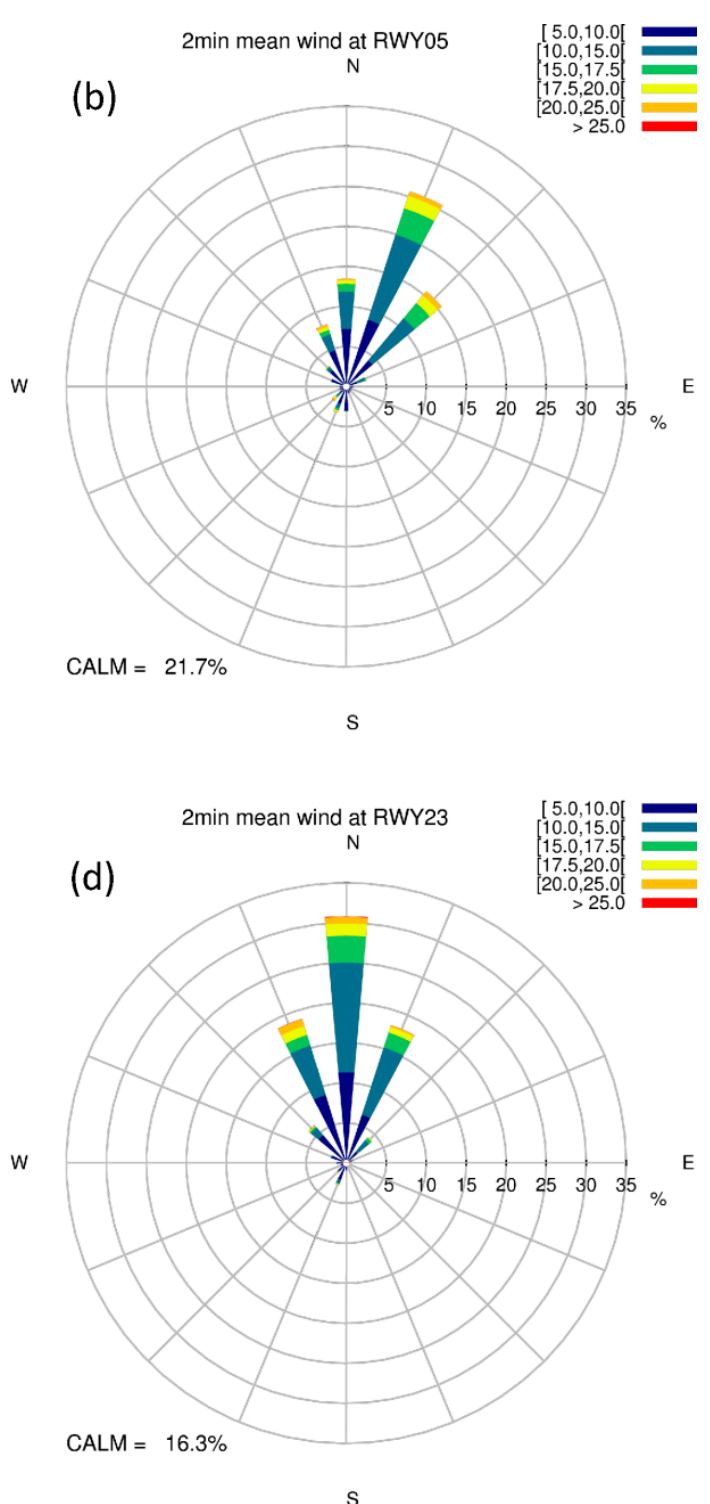

Figure 4. Wind roses screening the relative frequencies of occurrence (in percent) of the average 2-min wind speed at 10-m height, over the summertime period (April-September), at Rosario (RS) (a) and at three sites at the Madeira Airport: RWY05 (b), MID (c) and RWY23 (d). Six wind speed classes (in kt) are also shown (cf. legend), as well as the percent of calm $(<5 \mathrm{kt})$ events.

\subsection{Weather Types and Their Connection between Restriction of Landing and Take-Off Operations Due to Wind Limitations}

The landing and take-off operations at the Madeira airport have operating mandatory limitations related to wind conditions. For instance, limitations occur when the wind direction at $10 \mathrm{~m}$-height is from NNW to NE, depending on average 2-min wind speed and gust speed (see details in Appendix A). It is interesting to reinforce that the highest wind intensities occur for these wind directions (as shown in the previous section). In the present section, the link between the synoptic-scale patterns and the occurrence of the restriction episodes at MIA due to adverse winds is analysed. Table 1 summarizes the main features of the 20 WTs, whereas Figure 5 shows the four weather types responsible for the majority of the adverse winds at MIA, as well as the other four WTs responsible for the most severe events. All these regimes reflect the presence of the Azores high, with some variations on its strength and position. Besides, the first four WTs reveal an anticyclone with a shallow structure and induce 
NE near-surface winds over the Madeira Island (Figure 5a-d). However, at Z700, for WT1 and WT14 northerly winds are expected, while for WT2 easterly winds are likely.

Table 1. Main dynamical large-scale circulation features of the different weather types, with the following criteria in the Madeira Island area: deep (shallow) vertical structure corresponds to an angle between isobars and $700 \mathrm{hPa}$ geopotential height isolines lower (higher) than $45^{\circ}$, and large-scale mean flow direction refers to geostrophic wind flow at mean sea level pressure. The WTs responsible for the highest frequency of adverse winds at MIA are in bold.

\begin{tabular}{cc}
\hline Dynamical Features & Weather Types \\
\hline Deep anticyclonic north-easterly flow & $\mathbf{6}, \mathbf{1 3}, 16, \mathbf{1 8}, \mathbf{1 9}$ \\
Anticyclonic westerly flow & $3,7,10$ \\
Deep anticyclonic northerly flow & 9 \\
Shallow anticyclonic north-easterly flow & $\mathbf{1 , 2}, \mathbf{4}, \mathbf{1 1}, \mathbf{1 4}$ \\
Shallow anticyclonic north-westerly/northerly flow & 12,15 \\
Deep cyclonic westerly flow & $5,8,17$ \\
Blocking high southern flank & 20 \\
\hline
\end{tabular}

The other four regimes present a deep anticyclonic circulation, which is strongest for WT13. This WT is characterized by an intense Azores anticyclone (central MSLP above $1032 \mathrm{hPa}$ ), also apparent at Z700 (and at Z500, not shown), extending towards the Iberian Peninsula (Figure 5e). Consequently, the Madeira Island is exposed to anomalously strong northeasterly winds up to Z500, driven by the strong pressure gradient between the eastern North Atlantic and Northwestern Africa. In this case, wind speeds of at least $10 \mathrm{~ms}^{-1}$ are expected at summit level and the wind direction will be perpendicular (within 30 degrees) to the crest of the mountains throughout a deep layer of the troposphere. These conditions are favourable to the formation of vertically propagating mountain waves [32].

WT6 is associated with a high (trough) extending to Iberia at the surface (Z700) (Figure 5f). WT18 is characterized by the presence of an intense anticyclone (central MSLP above $1032 \mathrm{hPa}$ ) northeast of Azores expanded to the Gulf of Biscay (Figure 5g). In WT19, there is a slight strengthening and eastward migration of the Azores high, relative to the climatological position (Figure 5h). In both WT18 and WT19, the Z700 maxima are nearly above the maxima at MSLP, inducing NE winds up to Z700 over Madeira. Moreover, an intense high-pressure system is visible northeastwards of the Azores and extends towards the British Isles, with a Z700 trough slightly westwards of the MSLP maximum in association with WT16 (Figure S6). This regime originates NE winds near the surface and winds from $\mathrm{N}$ at Z700.

Throughout the year, and especially in summer, the most frequent regimes are WT1, WT11, WT2, WT14, and WT15 (Figure 6a), each with an average frequency greater than 22 days. In summer, the least frequent regimes are WT6, WT7, WT10, WT13 and W18, with a frequency of occurrence lower than 2 days on average (Figure 6a, Table S1). In winter, the relative frequencies of occurrence of the 20 WTs reveal a nearly uniform distribution. Nonetheless, the cyclonic regimes (W5, WT8 and WT17) are more frequent than in summer (Figure 6a, Tables S1 and S2), explaining the higher frequency of SW winds in winter relatively to summer months (compare Figure 4 and Figure S5). The annual frequencies show an intermediate distribution, as expected (Figure 6a). 
(a)

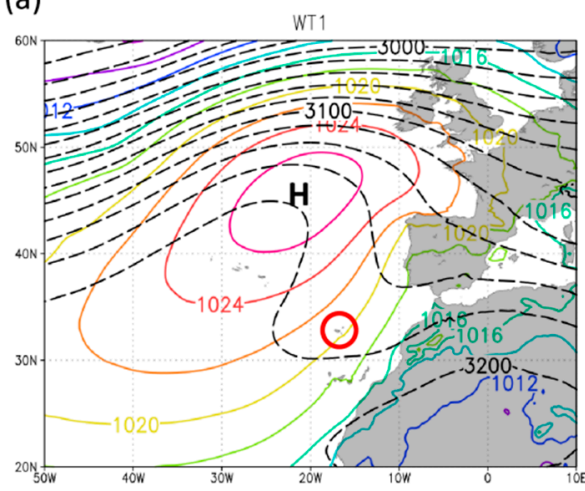

(c)

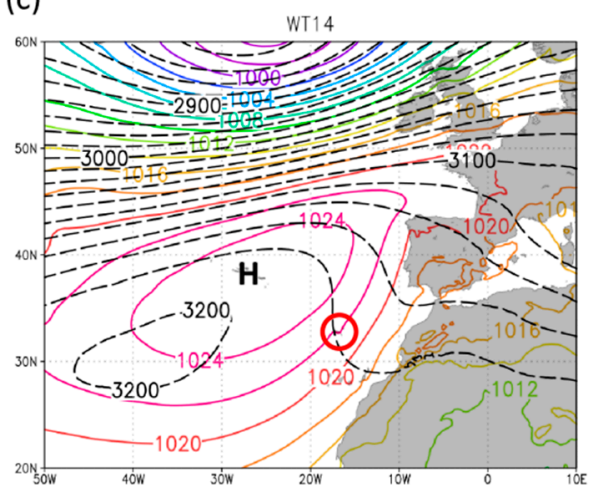

(e)

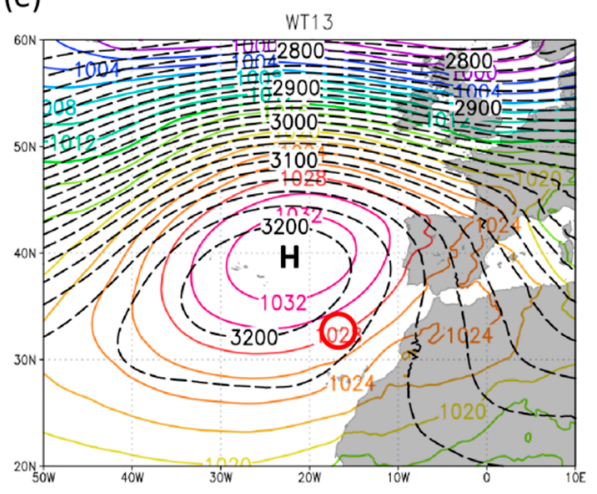

(g)

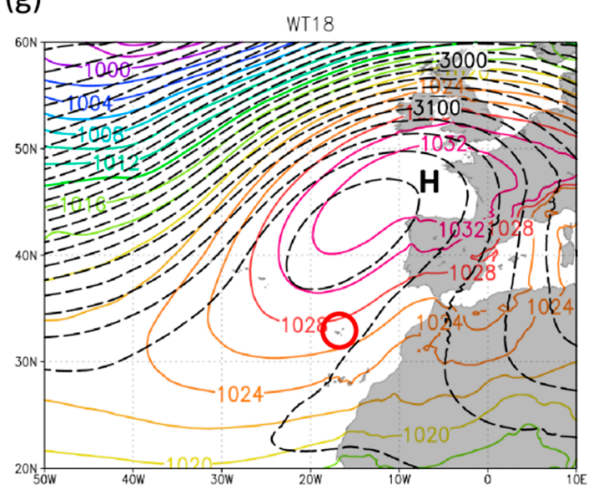

(b)

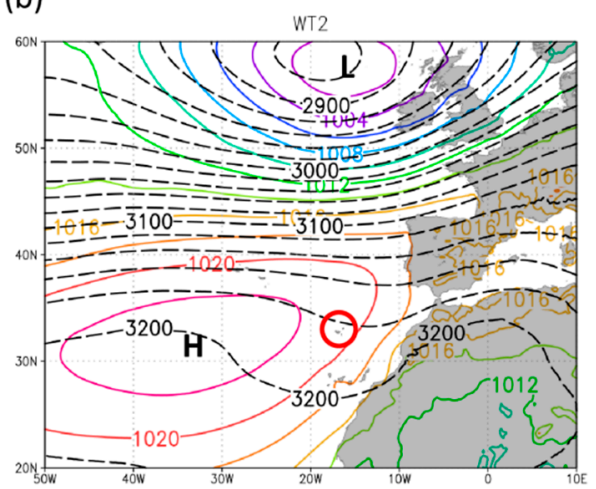

(d)

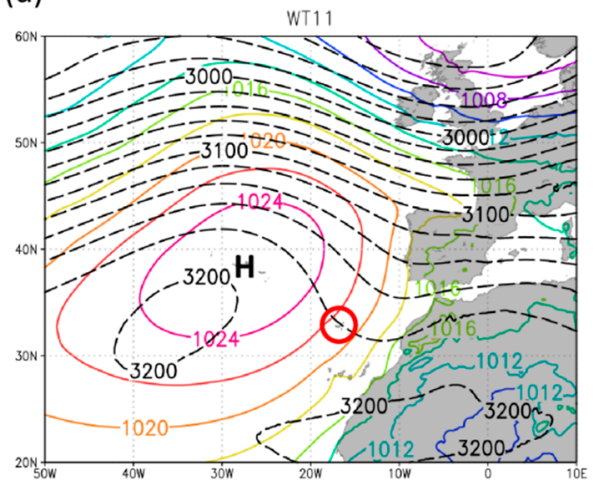

(f)

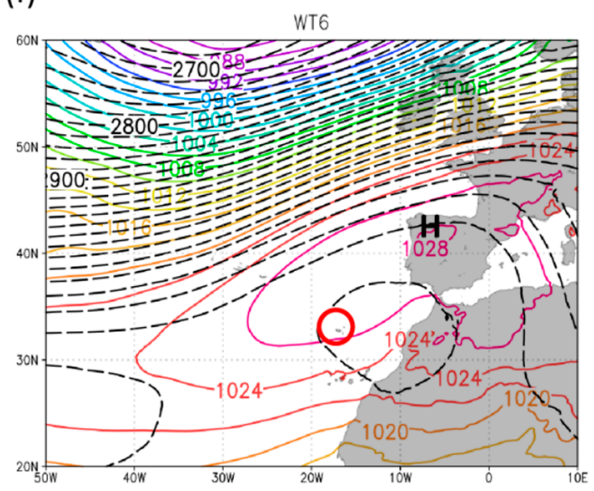

(h)

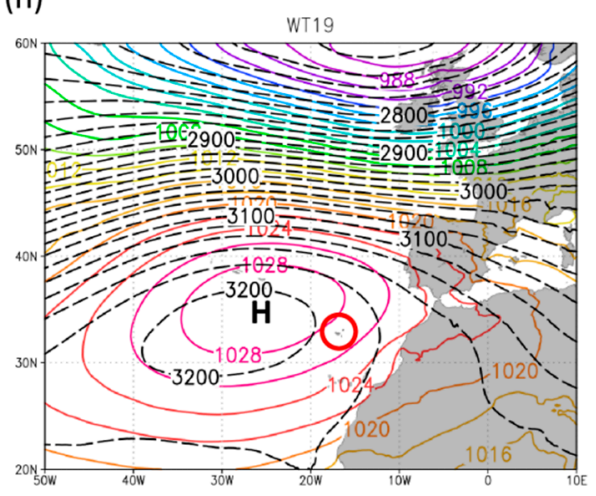

Figure 5. (a-h) Composites of the daily mean sea level pressure (solid contours) and $700 \mathrm{hPa}$ geopotential height (dashed contours) over the eastern North Atlantic and adjacent landmasses for the weather types (WT) most favourable to take-off/landing restrictions at the Madeira Airport. (a) WT1, (b) WT2, (c) WT14, (d) WT11, (e) WT13, (f) WT6, (g) WT18 and (h) WT19. The location of the Madeira Island is indicated by the red circles. 


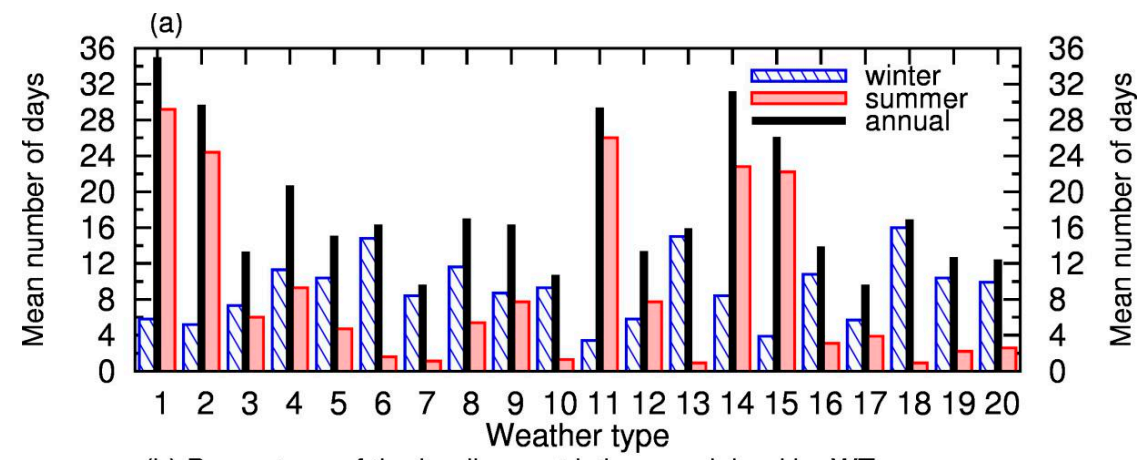

(b) Percentage of the landing restrictions explained by WT

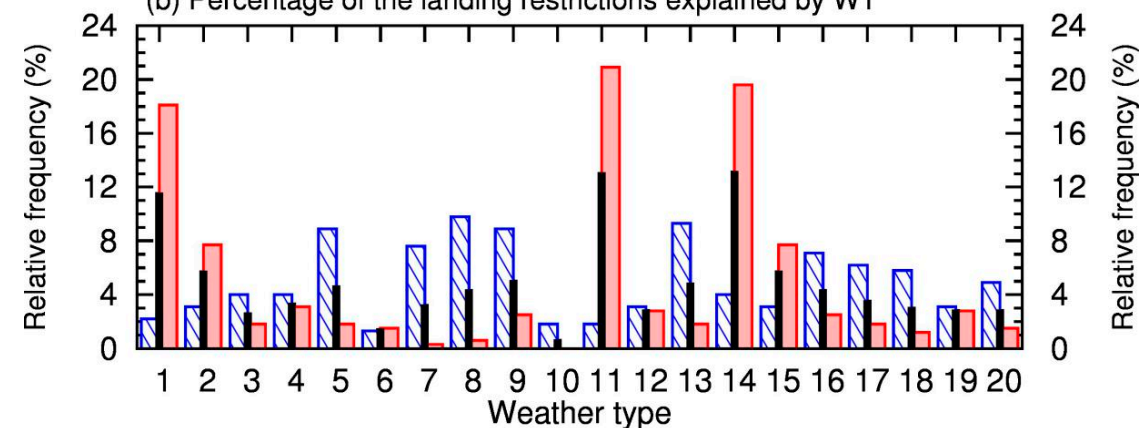

(c) Probability of occurrence of landing restriction event $(>1 \mathrm{~h})$ for WT

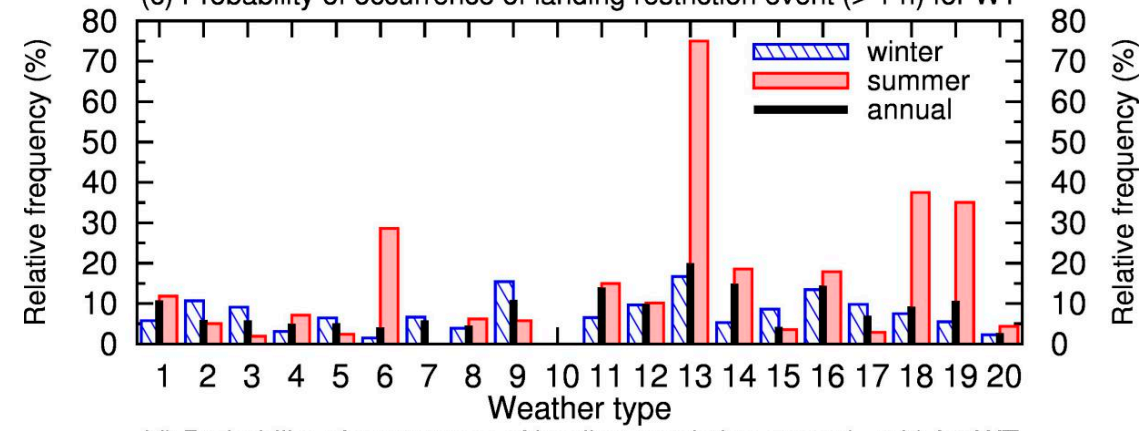

(d) Probability of occurrence of landing restriction event $(>6 \mathrm{~h})$ for WT

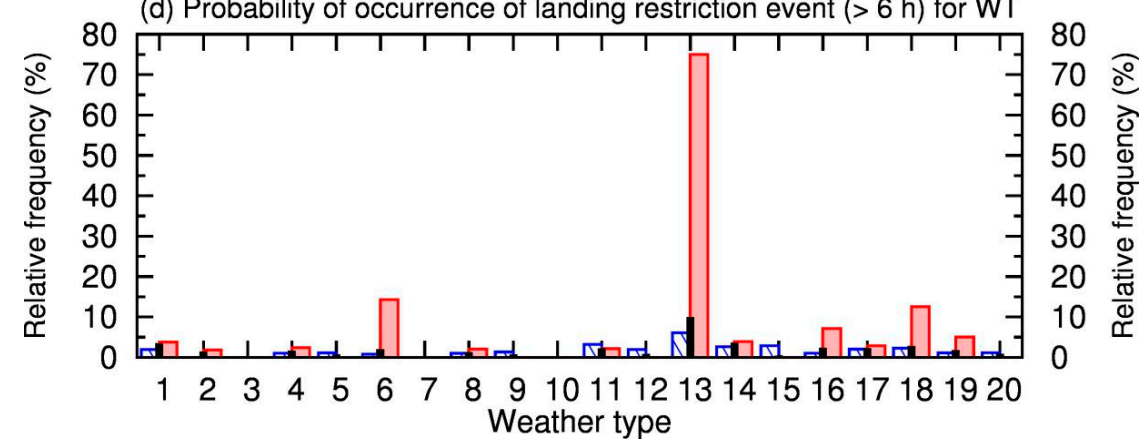

Figure 6. (a) Mean number of days of occurrence (in percent) by weather type (from WT1 to WT20) for wintertime (blue), summertime (red) and annual (black) periods. (b) Percentage of the total landing restrictions occurring for each WT. Probability of occurrence of a landing restriction event at MIA with a duration of more than (c) $1 \mathrm{~h}$ and (d) $6 \mathrm{~h}$, when a certain WT occurs.

In summer, nearly $60 \%$ of the landing restriction events are explained by the presence of WT11, WT14 and WT1 (Figure 6b), which are three of the most frequent regimes during this season. However, when one of these three WT establishes the probability of the occurrence of landing restriction event is highest for WT14 (19\%) and the smallest for WT1 (12\%) (Figure 6c). In other words, for days with WT14, only 19\% led to adverse winds at MIA. It is important to refer that these WTs are linked to the occurrence of strong gusts (above $35 \mathrm{kt}$ ), with a frequency varying between 6.4 and $8.3 \%$. Besides, 
the strongest gust $(53.7 \mathrm{kt})$ recorded at MIA during this season occurred in connection with WT14 (Table S1).

Although WT13 occurs only occasionally (Figure 6a), in the days under its influence the percentage of landing restriction events lasting at least $6 \mathrm{~h}$ is indeed very high (nearly 80\%) (Figure 6d). Furthermore, the highest percentage of strong gust events is related to this WT, namely gusts above $30 \mathrm{kt}$ or $40 \mathrm{kt}$ are expected in $75 \%$ or $38 \%$ of the time, respectively (Table S1). Despite the leading role played by WT13, there are other patterns with a low frequency of occurrence that can promote landing restriction events lasting more than 6 h, namely WT6, WT18, WT16 and WT19 (Figure 6d). Although no wind gusts above $40 \mathrm{kt}$ are expectable in association with these regimes, gusts above $35 \mathrm{kt}$ may occur (Table S1).

In winter, nearly $50 \%$ of the landing restriction events are fostered by the occurrence of three cyclonic regimes (W5, WT8 and WT17) and three deep anticyclonic regimes (WT9, WT13, and WT16) (Figure 6b). It is also noteworthy that a landing restriction event is more likely under the influence of one of these anticyclonic regimes than under the influence of the cyclonic WTs. For instance, for days with WT5, only $6 \%$ led to adverse winds at MIA, while $17 \%$ from all days under the influence of WT13 led to adverse winds at MIA (Figure 6c).

The temporal evolution (2010-2018) of the annual number of days with landing (Figure 7a) or take-off (Figure 7b) limitations due to adverse wind conditions at the RWY05 reveals that the former are much more frequent than the latter. Furthermore, there is a marked increase in the number of landing limitation events during the second half of the study period. This shift cannot be attributed to changes in the operating limitations procedures, as these remain invariant throughout this period. Still regarding the landing limitations, these episodes tend to be more frequent in summer than in winter, except for 2014, when the number of events of strong winds in summer was very low. The higher occurrence of these episodes in summer is consistent with the higher prevalence of Madeira wake events during this season [23]. The summer of 2016 was particularly affected by landing restrictions due to wind limitations at the Madeira Airport, with a peak of 34 days of landing limitations lasting more than $1 \mathrm{~h}$ and 10 days of episodes lasting more than $6 \mathrm{~h}$. Take-off restrictions also show a peak in the summer of 2016, but with a much lower number of occurrences (12 days) and only for episodes longer than $1 \mathrm{~h}$ (Figure 7). A similar tendency was verified for RWY23 (not shown). Moreover, in winter the events of air traffic restrictions due to wind limitations at the Madeira airport are considerably less frequent and less persistent than in summer (Figures $6 \mathrm{c}-\mathrm{d}$ and 7 ). For this reason and due to the greater impact of the adverse winds on the Island economy during summer months, the next sections will be concentrated only in summertime.

The average number of the WTs and the temporal evolution of the number of days of the WTs is shown in Figure 8 for summertime. To improve the clarity of the figure only the WTs responsible for the most adverse wind conditions at MIA are represented separately, while the other regimes are represented as "other". It is visible that WT13 and WT6 regimes were nearly absent from 2012 to 2014. On the contrary, these WTs were more frequent in 2016 and 2017. The frequency of other regimes leading to adverse wind conditions (WT14 and WT1) was exceedingly high in 2018 (35 days above average), and below average in 2012 (Figure 8a). The comparison of Figure 8a,b allows verifying the congruence between the restriction episodes and the synoptic environment. This comparison suggests that the anomalous high frequency of occurrence of WT6 and WT13 contributed to the remarkably high frequency of wind limitations at MIA in the summers of 2015 to 2017. Besides, in 2017, WT14, WT11, WT1 and WT2 also largely promoted adverse conditions at MIA. In 2015 and 2018, WT18, WT19 and WT16 showed a frequency of occurrence above average, thus playing an important role. In 2016, the abnormal frequency of WT14 and WT1 significantly contributed to wind limitations. Besides, although the frequency of WT11 was nearly normal, in this year, this WT promoted adverse conditions more often than usual. 

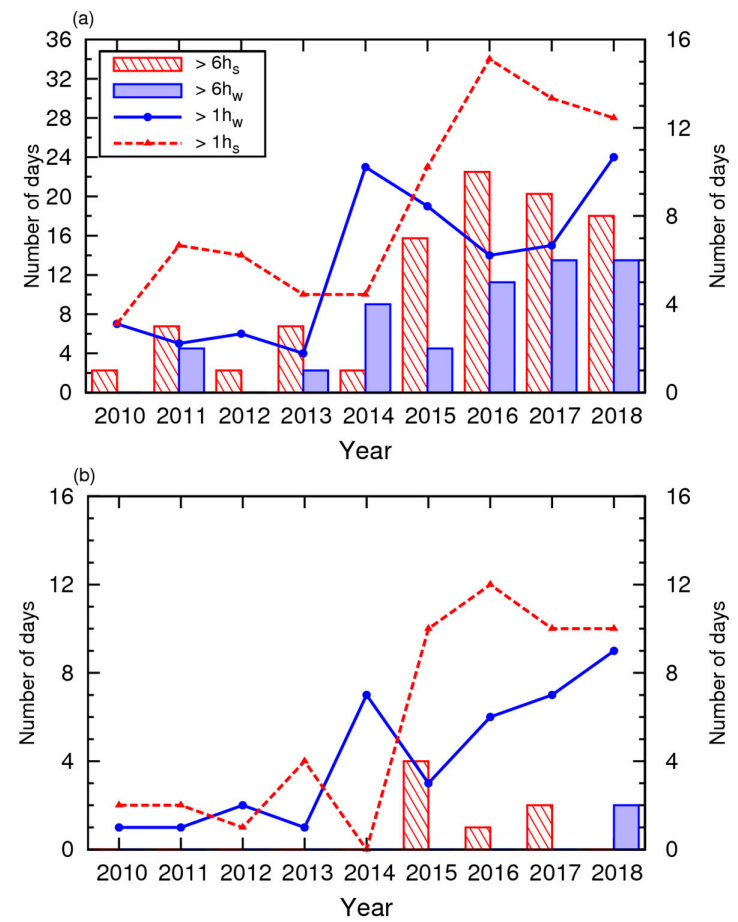

Figure 7. Chronogram (2010-2018) of the annual number of days with restrictions of (a) landing operations and (b) take-off operations lasting for more than $1 \mathrm{~h}$ (lines, left axis) or $6 \mathrm{~h}$ (bars, right axis) during summertime (red) and wintertime (blue) periods at the RWY05 site at the Madeira Airport.

(a)

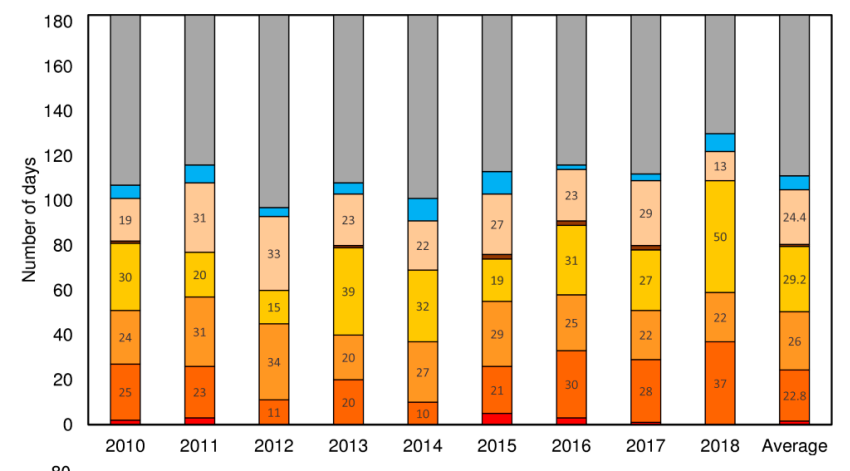

(b)

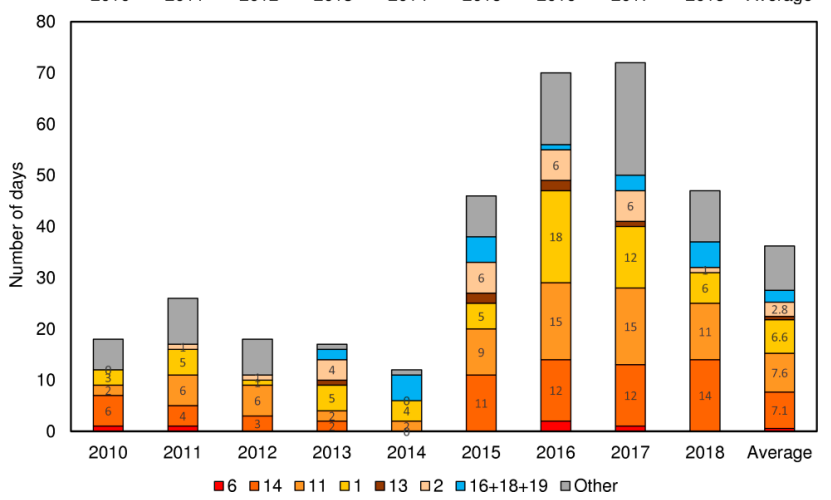

Figure 8. (a) Time evolution of the number of days of the WTs. The WTs responsible for the most adverse wind conditions at MIA are represented separately, while the remaining WTs are represented as "other". The average number of days of these WTs is also plotted (average bar). The number of days for WT14, WT11, WT1 and WT2 are also indicated. (b) Similar to (a), but for the days with restriction episodes lasting more than $1 \mathrm{~h}$. 


\subsection{A Case Study Analysis}

This section focuses on the episode of 7 August 2016, when several flights were cancelled and/or delayed after 2030 UTC and a missed approach event occurred at 2308 UTC at the MIA. On that day, the synoptic conditions were characterized by the WT13, thus supporting a strong upstream unidirectional flow over Madeira Island. In Section 3.2, it was shown that this WT supports the establishment of wind hazardous conditions at the MIA. This particular event is analysed using the AROME forecasts and observations to explore the interaction between the synoptic-scale forcing and the orographic effects that favoured these conditions. This case study also allows illustrating the mechanisms that foster the spatial variations of wind regime over the Madeira Island, shown in Section 3.1.

\subsubsection{Upstream Conditions and Flow Splitting}

In the shallow-water framework, used by several authors $[13,14,19,33,34]$ as an approximation to the real atmosphere, and for a two-layer atmosphere (a lower neutral layer and a stable layer above it), the flow response to an isolated symmetric mountain depends on the upstream inversion Froude number $\left(\mathrm{Fr}_{\mathrm{i}}=\mathrm{U}_{\mathrm{nm}} / \sqrt{\mathrm{g} / \mathrm{Z}_{\mathrm{i}}}\right)$ and on the ratio of mountain height to inversion height $\left(\mathrm{h}_{\mathrm{m}} / \mathrm{z}_{\mathrm{i}}\right)$, where $\mathrm{z}_{\mathrm{i}}$ is the inversion height, $\mathrm{g} \prime=\mathrm{g} \Delta \theta / \theta_{\mathrm{m}}, \mathrm{g}$ is the gravitational acceleration, $\Delta \theta$ is the potential temperature difference across the inversion, $\theta_{\mathrm{m}}$ is the mean potential temperature below $\mathrm{z}_{\mathrm{i}}$ and $U_{\mathrm{nm}}$ is the cross-mountain wind speed. Under this context, Schär and Smith [13] presented a flow regime diagram (their Figure 3) showing that for $\mathrm{Fr}_{\mathrm{i}}<1$ and for $\mathrm{h}_{\mathrm{m}} / \mathrm{z}_{\mathrm{i}}$ greater than a critical value (dependent on $\mathrm{Fr}_{\mathrm{i}}$ ) a strong wake will develop in connection with flow splitting and two hydraulic jumps (their regime III). These hydraulic jumps, also known as flank shocks or wake shocks, have a turbulent nature and occur in association with two wind speed maxima located on the opposite lateral edges of the obstacle.

Figure 9a depicts the time evolution of $\mathrm{Fr}_{\mathrm{i}}$ and $\mathrm{h}_{\mathrm{m}} / \mathrm{z}_{\mathrm{i}}$, where $\mathrm{h}_{\mathrm{m}}=1200 \mathrm{~m}$ represents the height of Madeira plateau according to the AROME orography. On 7 August 2016, according to the AROME forecasts, on the windward side (A50 point, see location in Figure 1), $\mathrm{Fr}_{\mathrm{i}}$ varies between 0.3 and 0.8 and $h_{m} / z_{i}$ fluctuates between 2 and 3.1, showing an increase after 12 UTC. Considering these two parameters and the regime diagram of the shallow water flow disturbed by an isolated obstacle (Figure 3 of Jiang and Smith [12]), a flow-splitting regime with flank shocks and a strong wake should be expected. Additionally, the non-dimensional mountain height $\left(\mathrm{M}=\mathrm{N} \mathrm{h}_{\mathrm{m}} / \mathrm{U}\right)$ varied between 1.7 and 2.8 during this day (not shown). Considering that the Madeira Island has an aspect ratio (mountain width perpendicular to the flow direction divided by the mountain width in the flow direction) of approximately 2.5 for northerly winds, the Epifanio [14] regime diagram (their Figure 2) also predicts favourable conditions to flow-splitting, wave breaking and lee vortex formation.

The increase of $h_{m} / z_{i}$ along the day (Figure $9 a$ ) reflects the lowering of the inversion layer, which is illustrated in Figure 9b. Between 03 and 12 UTC, $z_{i}$ is of about $570 \mathrm{~m}$ and decreases after 12 UTC, reaching a minimum value $(400 \mathrm{~m})$ at 23 UTC. Below the sharp inversion, a neutral layer is noticeable $\left(\theta_{\mathrm{m}}=294 \mathrm{~K}\right)$. The small fluctuations in $\mathrm{Fr}_{\mathrm{i}}$ are connected to variations in the inversion strength $(\Delta \theta$ varying between 5 and $9 \mathrm{~K}$ ) and the increase after 12 UTC is caused by the reinforcement of the wind speed near the inversion layer (not shown).

The 10-m wind gust observed and predicted by AROME in Madeira Island on 7 August 2016 is shown in Figure 10. A stagnation area is visible northwards of the island, where the flow is deflected laterally, also revealing a wind intensification on the western and eastern edges of the island. This pattern is a clear signature of flow splitting and is consistent with previous studies [12,13]. So, the high speeds on the edges of the Island reflect the flank shocks. In general, observations confirm the occurrence of strong gusts on the edges of the Island. At 03 UTC, the wind gust at northwestern and northeastern stations registered $30 \mathrm{kt}\left(\sim 15 \mathrm{~m} \mathrm{~s}^{-1}\right)$ and $20 \mathrm{kt}$, respectively. In the eastern region, AROME overestimates the wind gust at this time. Leeward of the Madeira mountain range, a reverse wake flow is developed. Moreover, to the southwest of the island, the AROME predicts the occurrence 
of a lee vortex (Figure S7). Due to the influence of the wake, the wind is feeble at the RS site $(<6 \mathrm{kt})$ and blows from the southwest (Figure 10a and Figure S8).

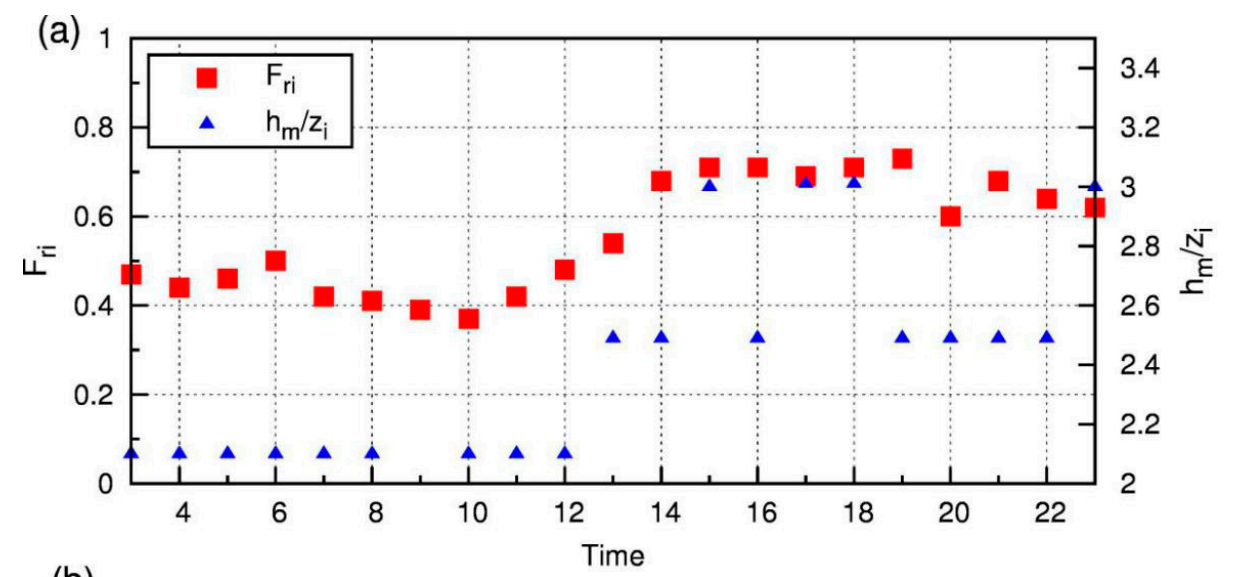

(b)

\section{Potential temperature $(\mathrm{K})$}

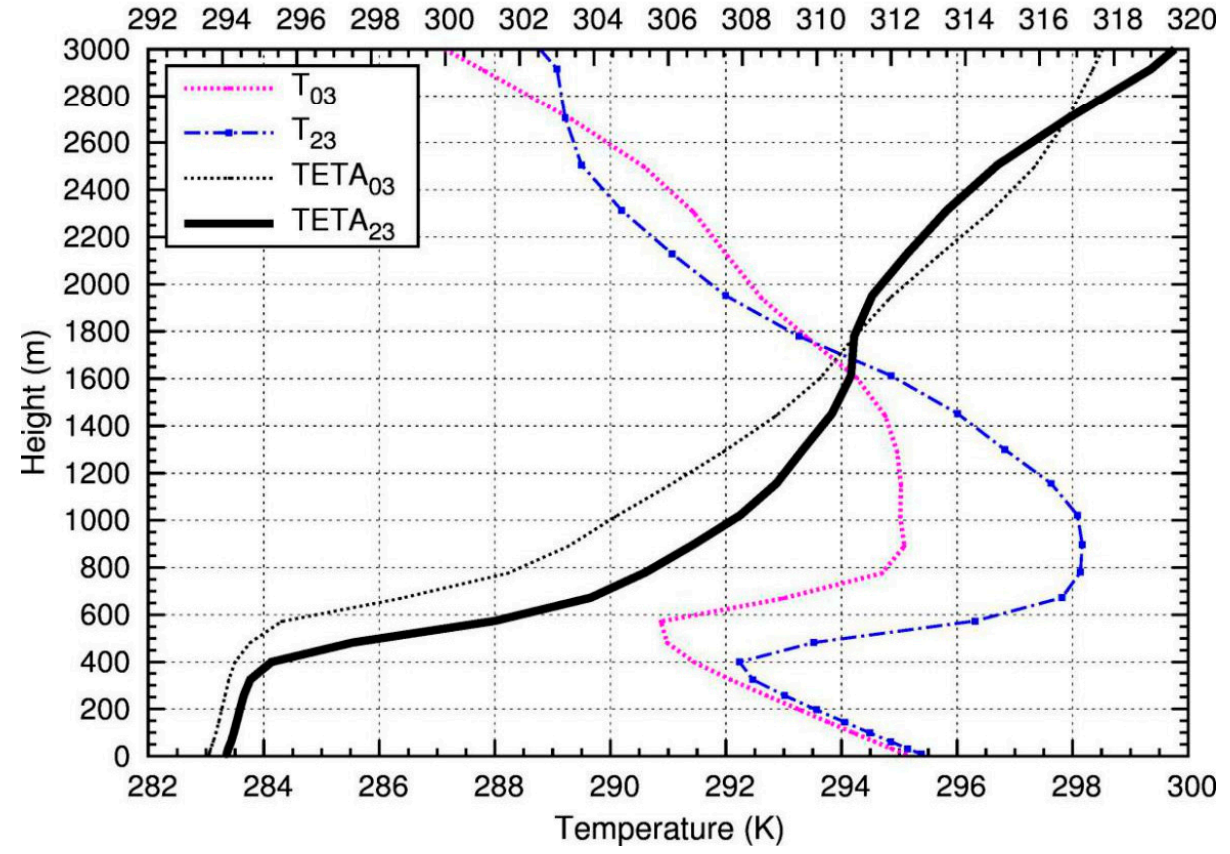

Figure 9. (a) Time evolution of $F r_{i}$ and $\mathrm{h}_{\mathrm{m}}$ /zi on 7 August 2016. The computation of these parameters was based on AROME forecasts at point A50 (see its location Figure 1a). (b) Vertical profile of temperature (T) and potential temperature (TETA) at point A50, derived from the AROME forecasts, valid at 03 UTC and 23 UTC, on 7 August 2016.

At 23 UTC, when the maximum gusts ( $\sim 43 \mathrm{kt})$ were registered at RS, AROME depicts strong gusts $(>35 \mathrm{kt})$ over the mountain range and on the eastern and western edges of the island, in accordance with observations (Figure 10b). This pattern reflects the reinforcement of the flow splitting, which was favoured by a strengthening of the flow stagnation $(<5 \mathrm{kt})$ on the windward side of the island. Moreover, this stagnation area was shifted to the southwest (relatively to the position at previous hours), consistently with a change of the upstream wind direction from NE to N (Figure 10). This outcome is consistent with the study of Nína et al. [35] that showed the impact of the upstream wind direction on the upstream blocking, as well as on the strength and position of the lee wake. 
(a) Gust (kt) at 3UTC
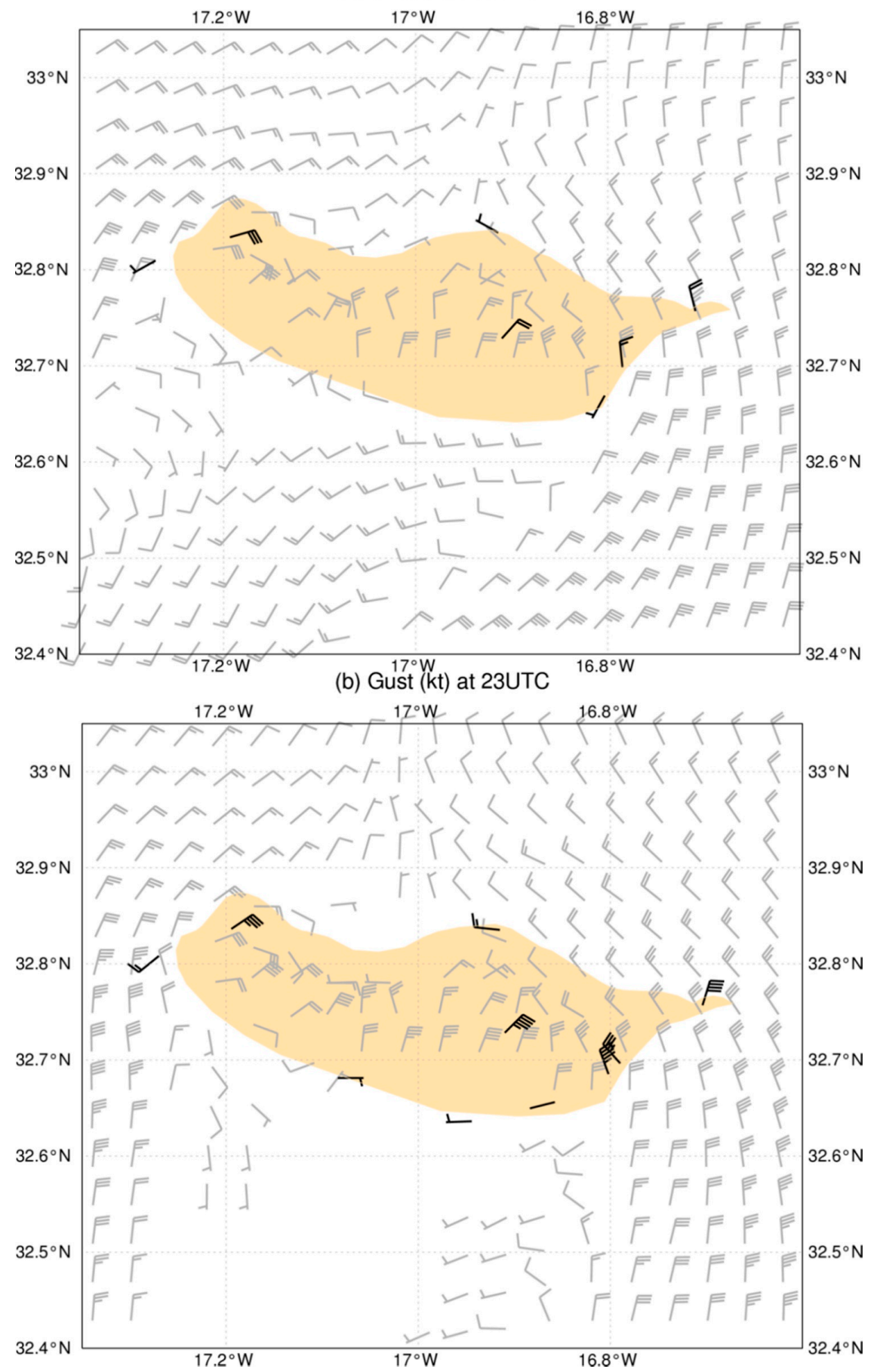

Figure 10. Observed (black barbs) and AROME forecast (grey barbs) of the wind gusts at 03 UTC (a) and 23 UTC (b) on 7 August 2016. In the area of the airport are represented only the barbs of the observations at RS site and RWY05.

At RWY05, wind strengthens until 06 UTC, decreasing sharply afterward, while wind direction changed from $\mathrm{N}$ to $\mathrm{S}$, with feeble winds ( $<6 \mathrm{kt}$ ) from S/SW until 18 UTC (Figure 11). At $23 \mathrm{UTC}$, and close to the time of the above-referred aircraft missed approach, wind gusts registered $32 \mathrm{kt}$ and $\sim 43 \mathrm{kt}$ at RWY05 and RS sites, respectively (Figure 11 and Figure S8). At locations nearby RWY05, the time evolution of the wind presents significant differences with respect to this location. At RS site, the wind speed varies between $3 \mathrm{kt}$ to $12 \mathrm{kt}$ until 21 UTC, increasing sharply after 21 UTC, when the 
wind direction changed to N (Figure S8). On the other hand, at RWY23, wind speeds of 18-25 kt, with gusts up to $31 \mathrm{kt}$, persisted until 12 UTC. Between 13 and 17 UTC, the wind speed weakened, as the direction changed first from $N$ to SW and then to SE. Finally, the wind started to blow from the north and intensified, reaching a peak between 21 and 23 UTC, with gusts of 33-35 kt (Figure S9). For these locations, these wind changes can be partially associated with the fluctuations in the wake position.
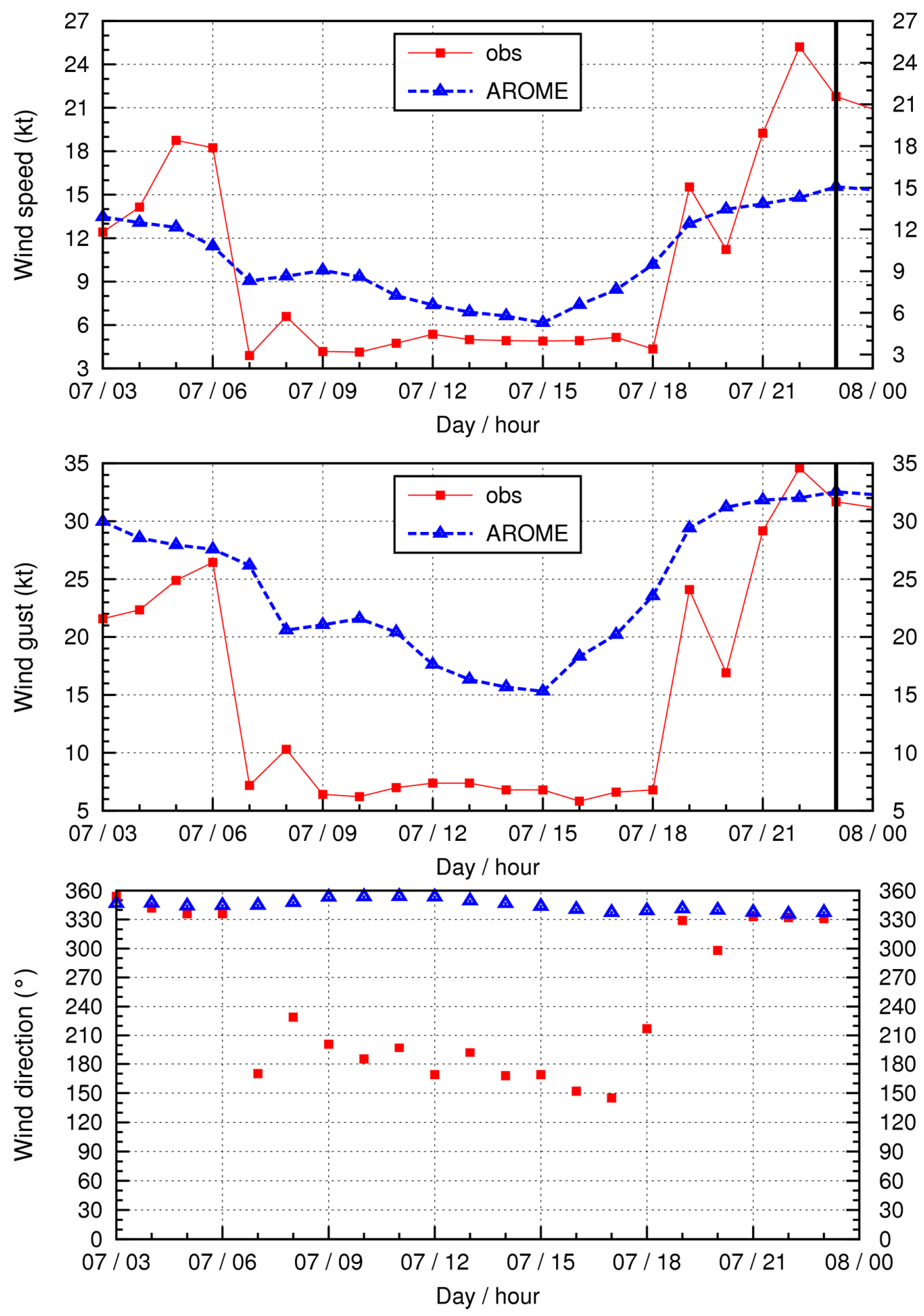

Figure 11. Time evolution of wind speed, wind gust and wind direction at 10-m height, from AROME forecast and observations at RWY05, on 7 August 2016. The time of a missed approach is marked as an impulse. 
Although the AROME model is able to predict the wake development, the Madeira airport is located in a region where wind varies strongly over short distances, due to its proximity to the wake and the region of maximum wind speed (caused by the flow splitting). This implies that a small phase error may cause large errors in the forecast of the wind speed and/or wind direction. This can explain the discrepancies between the observations and AROME forecasts in certain locations. For instance, at RWY05 and between 07 UTC and 18 UTC, the model overestimates the wind intensity and presents large errors in wind direction (Figure 11). Nevertheless, at the RS site, there is reasonable agreement between the model forecast and observations, except for the underestimation of the wind speed after 21 UTC (Figure S8). In addition, the model is able to forecast the reinforcement of the wind gust after 20 UTC at the airport and in its vicinity (Figure 11, Figures S8 and S9).

\subsubsection{Vertical Structure}

The vertical cross-sections of potential temperature and wind predicted by AROME on 7 August 2016 at 23 UTC are presented in Figure 12. The first cross-section intersects the eastern plateau passing through Funchal and the second one passes through the Madeira airport (see locations in Figure 1a,b). The presence of temperature inversion between 400 and $800 \mathrm{~m}$, identifiable by the strong vertical gradient in the potential temperature (close isentropes), is noticeable in the upstream region. Figure 12a displays NW winds below the inversion and strong NE winds $\left(12-15 \mathrm{~m} \mathrm{~s}^{-1}\right)$ above the inversion top, north of the mountain range. The sloping isentropes on the lee side of the island (Figure 12a) are also noticeable, which is consistent with strong downward wind (with maximum $-2 \mathrm{~ms}^{-1}$ ) in the layer below $4 \mathrm{~km}$ AGL (Figure 12c), caused by the vertically propagating mountain wave. It is interesting to note that based on the International Civil Aviation Organization (ICAO) guidelines, a mountain wave is deemed "moderate" whenever downward vertical wind varies between 1.75 a $3.0 \mathrm{~ms}^{-1}$ [36]. Figure 12 also depicts the descending isentropes and strong downwards motion over the lee slope close to the Madeira airport. In this region, leeward of the mountain (up to $20 \mathrm{~km}$ to SE) and below $1500 \mathrm{~m}$ prevails N/NE winds reaching $35 \mathrm{kt}$. Helmis et al. [37] showed that strong downslope winds over the east slope of Hymettus Mountain were associated with turbulence within the first $600 \mathrm{~m}$ above ground and high surface winds. The downslope winds predicted by AROME (Figure 12d) might also have been associated with turbulence and contributed to reinforce the surface winds near the MIA, contributing to the occurrence of the missed approach event (see Figure 11). On the windward side of the mountain, the flow stagnation $(<5 \mathrm{kt}$ ) is visible up to $700 \mathrm{~m}$ above ground (compare with Figure 10). The signature of mountain waves was present throughout the day. However, during the period of weak winds (between 12 and 15 UTC) at the MIA, these waves are less energetic and the downslope winds are much weaker $\left(<0.4 \mathrm{~ms}^{-1}\right)$, as illustrated in Figure S10. It is also interesting to notice that at 15 UTC, the downward motion develops on the leeward side (near Funchal), but only above an altitude of $800 \mathrm{~m}$ (Figure S10a). 

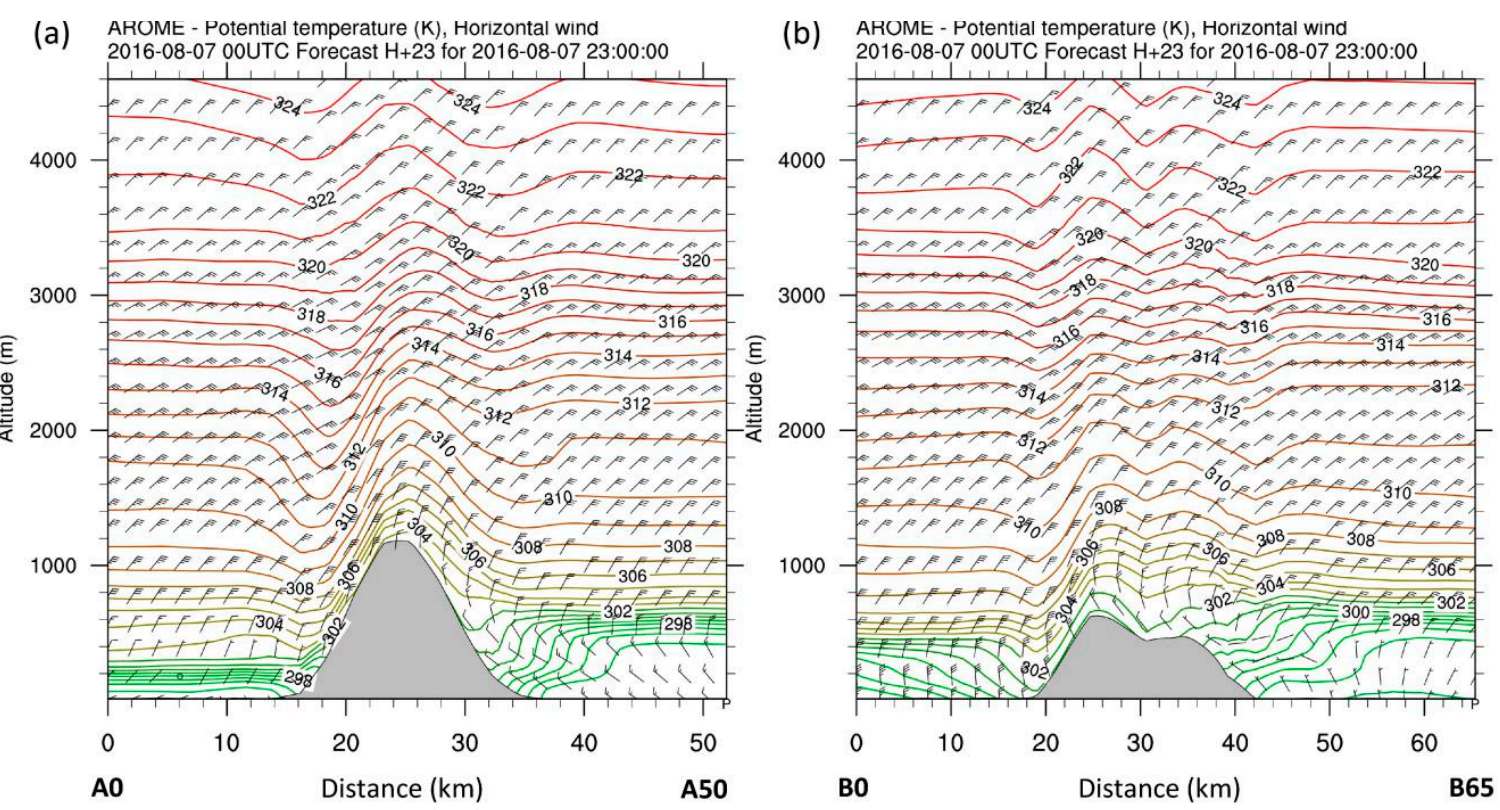

(c) AROME - Vertical Velocity, Cross-barrier wind
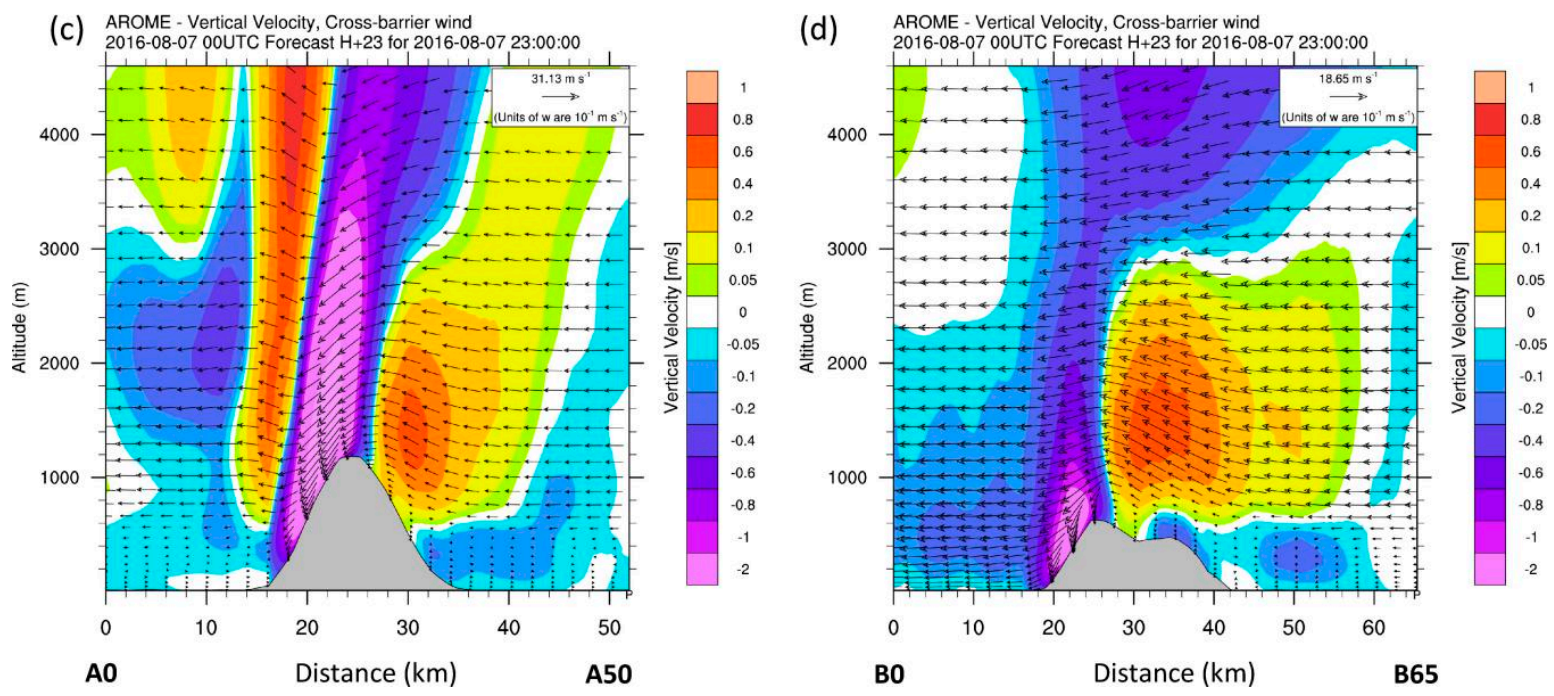

Figure 12. AROME vertical cross-sections at 23 UTC on 7 august 2016, along the horizontal axis A50-A0 $(\mathbf{a}, \mathbf{c})$ and B65-B0 $(\mathbf{b}, \mathbf{d})$. (a,b) Potential temperature (Isentropes interval is $1 \mathrm{~K}$ ) and horizontal wind $(\mathrm{kt})$. (c,d) vertical velocity $(\mathrm{w})$ and cross-barrier wind. Shading represents $\mathrm{w}$ in $\mathrm{m} \mathrm{s}^{-1}$, positive values indicate upward vertical wind and negative values represent downward vertical wind. The locations of lines A50-A0 and B65-B0 are depicted respectively in Figure 1a,b. On the left panel, the distance of $14 \mathrm{~km}$ corresponds to the Funchal location. On the right panel, the distance of $20 \mathrm{~km}$ corresponds to the MIA location. The cross-barrier wind $\left(\mathrm{w}, \mathrm{v}_{\mathrm{c}}\right)$ is represented in arrows, where $\mathrm{v}_{\mathrm{c}}$ is the horizontal wind parallel to the cross-section.

\subsection{Model Verification}

In order to assess the performance of the AROME wind forecasts at Madeira Island, several skill scores were calculated, comparing observations and hourly forecasts of wind at 10-m height. This analysis was performed for summer months from June to August, when wake episodes are more frequent [23], and for the 3-year period of 2015-2017. The errors of wind direction were computed following the methodology used in previous studies $[8,38]$. For wind speed and gust were computed the root mean square error (RMSE), mean absolute error (MAE), and the correlation (r), also known as Pearson's correlation coefficient. These scores are widely used in forecast verification [39]. The average 
values of observations $\left(\mathrm{o}_{\mathrm{m}}\right)$ and forecasts $\left(\mathrm{p}_{\mathrm{m}}\right)$ were also computed. Finally, a normalized RMSE $\left(\mathrm{RMSE}_{\mathrm{N}}\right)$, defined as RMSE $/ \mathrm{o}_{\mathrm{m}}$, was derived.

According to the ICAO guidelines, wind speed forecast errors should be less than $5 \mathrm{kt}$ [36]. In fact, at the MIA, AROME has RMSE values below $5 \mathrm{kt}\left(2.5 \mathrm{~m} \mathrm{~s}^{-1}\right)$. The exception is RWY23, where the RMSE is $5.2 \mathrm{kt}$ and the model has a bias of $1.2 \mathrm{kt}$. Elsewhere on the island, the RMSE is less than $5.4 \mathrm{kt}$. The exception is station 980, in the western part of the island, where, on average, the highest wind speeds are observed. In general, AROME underestimates wind speed on Madeira Island, especially on its western edge and near its highest mountain peak (Table 2).

Table 2. Skill scores of hourly forecasts for mean wind speed at different locations of the Madeira Island (see locations in Figure 1). The values of root-mean-squared error (RMSE), mean absolute error (MAE), average values of observations $\left(\mathrm{o}_{\mathrm{m}}\right)$ and forecasts $\left(\mathrm{p}_{\mathrm{m}}\right)$ are displayed in $\mathrm{m} \mathrm{s}^{-1}$ and $\mathrm{kt}$ (in parenthesis). The normalized RMSE (RMSE ${ }_{N}$ ), defined as RMSE/ $\mathrm{o}_{\mathrm{m}}$, and the correlation coefficient, $\mathrm{r}$, are also shown.

\begin{tabular}{ccccccc}
\hline Site & RMSE & MAE & $\mathbf{o}_{\mathbf{m}}$ & $\mathbf{p}_{\mathbf{m}}$ & RMSE $_{\mathbf{N}}$ & $\mathbf{r}$ \\
\hline 05 & $2.5(4.9)$ & $2.0(3.9)$ & $5.5(10.7)$ & $4.7(9.1)$ & 0.46 & 0.62 \\
RS & $2.2(4.3)$ & $1.7(3.4)$ & $4.9(9.5)$ & $4.1(7.9)$ & 0.45 & 0.70 \\
MID & $2.4(4.7)$ & $1.9(3.8)$ & $5.8(11.3)$ & $4.5(8.7)$ & 0.41 & 0.75 \\
23 & $2.7(5.2)$ & $2.1(4.2)$ & $6.2(12.1)$ & $4.5(8.7)$ & 0.43 & 0.73 \\
960 & $1.3(2.4)$ & $1.0(1.9)$ & $2.1(4.1)$ & $2.3(4.5)$ & 0.59 & 0.54 \\
973 & $2.8(5.3)$ & $2.1(4.0)$ & $5.1(9.8)$ & $3.3(6.4)$ & 0.54 & 0.78 \\
978 & $1.6(3.2)$ & $1.2(2.4)$ & $6.3(12.3)$ & $6.3(12.1)$ & 0.26 & 0.78 \\
986 & $1.7(3.3)$ & $1.2(2.3)$ & $1.9(3.7)$ & $1.5(3.0)$ & 0.89 & 0.16 \\
522 & $0.9(1.8)$ & $0.6(1.2)$ & $1.3(2.5)$ & $1.4(2.8)$ & 0.71 & 0.62 \\
524 & $1.3(2.6)$ & $1.0(1.9)$ & $5.4(10.4)$ & $4.9(9.6)$ & 0.25 & 0.74 \\
980 & $5.0(9.7)$ & $4.2(8.2)$ & $8.5(16.5)$ & $4.5(8.8)$ & 0.59 & 0.84 \\
\hline
\end{tabular}

Table 3 shows that on average AROME overestimates the wind gust, presenting values of RMSE between $3.1 \mathrm{kt}$ and $7.6 \mathrm{kt}\left(\sim 3.8 \mathrm{~m} \mathrm{~s}^{-1}\right)$. The exceptions occur in stations in the west and east edges, where the model underestimates the wind gust. In these two stations, the highest gust values are observed (on average $\geq 21 \mathrm{kt}$ ). The values of $r$ and $\mathrm{RMSE}_{\mathrm{N}}$ show that AROME forecasts of wind gust present a greater skill than those of mean wind speed (Tables 2 and 3).

Table 3. Skill scores of hourly forecasts for wind gust at different locations of the Madeira Island (see locations in Figure 1a). The values of root-mean-squared error (RMSE), mean absolute error (MAE), average values of observations $\left(\mathrm{o}_{\mathrm{m}}\right)$ and forecasts $\left(\mathrm{p}_{\mathrm{m}}\right)$ are displayed in $\mathrm{m} \mathrm{s}^{-1}$ and $\mathrm{kt}$ (in parenthesis). The normalized RMSE $\left(\mathrm{RMSE}_{\mathrm{N}}\right)$, defined as RMSE/ $\mathrm{o}_{\mathrm{m}}$, and the correlation coefficient, $\mathrm{r}$, are also shown.

\begin{tabular}{ccccccc}
\hline Site & RMSE & MAE & $\mathbf{o}_{\mathbf{m}}$ & $\mathbf{p}_{\mathbf{m}}$ & RMSE $_{\mathbf{N}}$ & $\mathbf{r}$ \\
\hline 05 & $3.9(7.6)$ & $2.9(5.7)$ & $8.4(16.4)$ & $10.2(19.7)$ & 0.46 & 0.66 \\
RS & $3.2(6.2)$ & $2.4(4.7)$ & $7.8(15.1)$ & $8.5(16.5)$ & 0.41 & 0.76 \\
MID & $3.2(6.2)$ & $2.4(4.7)$ & $9.0(17.5)$ & $10.2(19.8)$ & 0.35 & 0.78 \\
23 & $2.8(5.5)$ & $2.2(4.3)$ & $9.5(18.5)$ & $10.2(19.8)$ & 0.30 & 0.79 \\
960 & $1.6(3.1)$ & $1.2(2.4)$ & $4.0(7.8)$ & $4.1(8.0)$ & 0.40 & 0.64 \\
973 & $3.3(6.3)$ & $2.6(5.0)$ & $7.1(13.8)$ & $8.1(15.8)$ & 0.46 & 0.78 \\
978 & $2.7(5.3)$ & $2.3(4.4)$ & $10.8(21.0)$ & $8.9(17.3)$ & 0.25 & 0.86 \\
986 & $2.3(4.5)$ & $1.8(3.4)$ & $3.2(6.2)$ & $3.5(6.9)$ & 0.72 & 0.24 \\
522 & $1.7(3.4)$ & $1.2(2.3)$ & $2.7(5.2)$ & $3.3(6.3)$ & 0.66 & 0.65 \\
524 & $1.6(3.1)$ & $1.2(2.4)$ & $8.1(15.7)$ & $8.4(16.3)$ & 0.20 & 0.81 \\
980 & $3.3(6.5)$ & $2.7(5.3)$ & $11.1(21.5)$ & $9.9(19.3)$ & 0.30 & 0.82 \\
\hline
\end{tabular}

Furthermore, the model presents a higher performance in regions where strong winds are more frequent than where the flow stagnation or wake commonly develops. This result is also valid for wind direction. For instance, in the mountain station (973) and on the island edges (stations 980, 978 and RWY23), the wind direction MAE varies between $14^{\circ}$ and $21^{\circ}$ (see locations in Figure 1). On the 
other hand, the lowest skill is found in the southern region (station 986), where MAE and RMSE for wind direction are $61^{\circ}$ and $77^{\circ}$, respectively (Table 4). At the airport, and nearby, the highest RMSE is found at the RS site and the highest MAE occurs at RWY05. Thus, the percentage of large errors $\left(>40^{\circ}\right)$ in wind direction is higher at RS than in RWY05. These locations are often in or close to the island wake (which would correspond to weak winds), so a small error $(<5 \mathrm{~km})$ in wake position will cause large forecast errors. This explains the lowest skill of the forecasts of wind direction in these two sites, as occurred at the RS site at 03 UTC on 7 August (see Figure 10a).

Table 4. Skill scores of hourly forecasts for wind direction $\left({ }^{\circ}\right)$ at different locations of the Madeira Island.

\begin{tabular}{ccc}
\hline Site & RMSE & MAE \\
\hline 05 & 33.2 & 29.5 \\
RS & 35.8 & 26.7 \\
MID & 26.7 & 23.9 \\
23 & 16.6 & 12.8 \\
960 & 38.8 & 33.4 \\
973 & 26.9 & 21.4 \\
978 & 19.9 & 14.1 \\
986 & 77.1 & 61.3 \\
522 & 49.6 & 29.0 \\
524 & 16.1 & 13.4 \\
980 & 20.2 & 16.1 \\
\hline
\end{tabular}

\section{Summary and Conclusions}

The landing and take-off operations at the Madeira International Airport (MIA) have operating mandatory limitations related to adverse wind conditions. These conditions are less frequent and persistent in winter than in summer. The present study established a link between these adverse winds at the MIA and the synoptic-scale circulation, using a weather type (WT) classification, which allows identifying twenty WTs.

During the extended winter period (October-March), the relative frequencies of occurrence of the 20 WTs reveal a nearly uniform distribution, being the cyclonic regimes were more frequent than in summer. On the other hand, during the extended summer period (April-September), five anticyclonic WTs are predominant, cumulatively representing nearly $70 \%$ of days. In summer, nearly $60 \%$ of the landing restriction events are associated with three of these WTs (WT14, WT11 and WT1). However, for the days with WT14, only 19\% led to adverse winds at MIA. For the other WTs, this frequency decreases to $15 \%$ and $12 \%$, respectively, for WT11 and WT1. These three regimes reflect the presence of the Azores high with a vertically shallow structure, despite some variations in their strength and position. These WTs induce NNE/NE winds near the surface over the Madeira Island, with the wind backing up to $700 \mathrm{hPa}$. This backing is maximum (nearly 90 degrees) for WT11.

The prevalence of NNE/NE inflow over Madeira favours the occurrence of an upstream flow stagnation in its northern (windward) side, explaining the prevalence of weak winds in this region. Concurrently, the flow splitting phenomenon leads to a wind intensification on the western and eastern regions (lateral flank shocks), confirmed by the highest wind records, and the development of a lee wake. Since the MIA lies on the island's south-eastern coast, the wind conditions at the MIA are strongly influenced by the position of the lee wake and/or eastern flank shock.

The most severe and longer-lasting wind conditions at the MIA, with a higher frequency of gusts above $40 \mathrm{kt}$, arises under the influence of WT13. This regime reveals an intensification and eastward migration of the Azores high, with respect to its climatological position. Another three WTs were identified as responsible for adverse wind conditions at the MIA, namely WT18, WT19 and WT6. The high-pressure systems in these regimes reveal a strengthening, and either a north-eastward (WT18) or eastward shift relative to the average conditions. Furthermore, these four WTs have an important common characteristic, i.e., the maximum $700 \mathrm{hPa}$ or $500 \mathrm{hPa}$ geopotential height is positioned nearly 
above the maximum at the MSLP level. This indicates that the anticyclonic development extends to the mid-troposphere and, consequently, induces upstream anomalously strong NNE/NE winds near and above the mountaintop level. These conditions in the presence of strong stable stratification, which is fostered by strong anticyclones, favour the development of strong downslope winds [37].

The temporal evolution of adverse wind conditions at the MIA in recent years was also analysed. During the extended summer, in the 2015-2018 period, the number of days affected by these limitations has more than doubled compared to previous years (2010-2014). This growth was mostly driven by the reinforcement and eastward/north-eastward expansion of the Azores anticyclone, identifiable by the anomalously high frequency of the corresponding WTs. For instance, in 2018, the abnormal frequency of occurrence of WT14 has the greatest contribution to trigger adverse winds at the MIA. In 2015, the most adverse WTs (WT13, WT6, WT18, WT19) totalized 12 days (7 above average). On the other hand, the WT13 was absent in 2011, 2012 and 2014, when the adverse wind events were less frequent than after 2014.

The operational AROME model was used to better understand the triggering mechanisms of the adverse winds at the MIA on a day under the influence of an intense Azores high (typical of WT13). During that day, several flights were cancelled and/or delayed and a missed approach event occurred. During this severe wind episode, there was a reasonable agreement between forecasts and observations of wind gust at the MIA. However, the model overestimates the wind gust when the wind speed is less than $10 \mathrm{kt}$.

According to the AROME forecasts, during this episode, the upstream conditions were characterized by a low-level temperature inversion and by a Froude number varying between 0.4 and 0.8 . These conditions are prone to flow-splitting, wave breaking and lee wake development. Accordingly, AROME forecasts of wind at $10 \mathrm{~m}$-height identify a stagnation area northwards of the island and a flow splitting signature, with a wind intensification on the island lateral (eastward/westward) flanks. The lee wake to the south of the island was also predicted by AROME. Due to its location, throughout the day, the MIA was exposed to either weak winds, as the wake is shifted eastwards, or strong winds, associated with the flow splitting. In addition, the period of strongest winds (with gusts above $40 \mathrm{kt}$ ) at the MIA coincides with the strengthening of upstream stagnation and the consequent reinforcement of the flow splitting. Moreover, during this period, the AROME predicted strong downslope winds $\left(\sim-2 \mathrm{~m} \mathrm{~s}^{-1}\right)$, reaching the vicinity of the Madeira airport, in association with large-amplitude mountain waves. These results suggest that the presence of downslope winds reaching low levels can be a useful predictor of severe wind conditions at the MIA. However, in order to validate this hypothesis, other episodes must be analysed and, more importantly, the predictions of vertical wind velocities should be compared to the measurements provided by remote sensing equipment, such as sodars [37]. Therefore, it would be very useful to conduct a field campaign, ideally during the summer months.

Although not necessary for the development of downslope windstorms, the presence of a critical level or wave breaking tends to increase the likelihood and strength of windstorms [40,41]. Moreover, the presence of critical levels induced by directional wind shear plays a crucial role in triggering mountain-wave turbulence [42,43]. The occurrence of a strong temperature inversion also plays an important role in fostering the formation of downslope winds and rotors [34,37,40]. Thus, in the future, it would be imperative to explore the possible connection between these phenomena and the strengthening of winds at the MIA. Thus, it would be necessary to perform a climatological study to characterize the upstream environment, taking into account several ingredients, such as the formation of critical levels and their heights, as well as temperature inversions and their strengths. For this purpose, radiosonde observations in the Porto Santo Island (northeastwards of Madeira) would be very valuable.

Lastly, this study presents an assessment of the AROME 10-m height wind forecasts on Madeira Island. This analysis was carried out for the 3-year period of 2015-2017, during the months of June to August, when wake episodes are more prevalent. On average, AROME overestimates the wind gust, with RMSE ranging between $1.6 \mathrm{~m} \mathrm{~s}^{-1}$ and $3.9 \mathrm{~m} \mathrm{~s}^{-1}(\sim 7.6 \mathrm{kt})$. The exceptions occur in stations 
on the west and east edges, where the model underestimates the wind gust. At the MIA, the RMSE of wind gust varies between $2.8 \mathrm{~m} \mathrm{~s}^{-1}$ (RWY23) and $3.9 \mathrm{~m} \mathrm{~s}^{-1}$ (RWY05). Regarding the mean wind speed, the RMSE is $2.2-2.7 \mathrm{~m} \mathrm{~s}^{-1}$. The wind direction errors are small (RMSE $<20^{\circ}$ ) in regions where moderate to strong winds prevail, namely in RWY23 and on the flanks of the island. Moreover, in these locations, the Pearson correlation exceeds 0.7 for wind speed and wind gust. On the other hand, in locations where weak winds are more frequent due to the upstream stagnation or to the wake influence, the RMSE for wind direction varies between $30^{\circ}$ and $77^{\circ}$, whereas the correlations between observation and forecasts decrease significantly. The difficulty of NWP models to correctly predict weak winds is a widely recognized limitation $[8,38]$. This limitation has a great impact in the area of the MIA, since this airport is located in a region where wind varies strongly over short distances, due to its proximity to the wake and the region of maximum wind speed (caused by the flow splitting). As the island's very complex topography can significantly influence the precise location of these structures, higher resolutions of the NWP models may be critical to increase forecast accuracy. In the lower troposphere, turbulence and wind shear play a crucial role and can be potentially dangerous during landing and take-off operations. Therefore, in the future, it would be important to validate wind forecasts in the lower troposphere using data from Aircraft Meteorological Data Reports (AMDAR).

Supplementary Materials: The following are available online at http://www.mdpi.com/2073-4433/11/11/1257/s1, Figure S1. Wind roses screening the relative frequencies of occurrence (in percent) of the average 10-min wind (in kt, $\sim 0.51 \mathrm{~m} \mathrm{~s}^{-1}$ ) at the different locations of the Madeira Island, in summer (April-September). Locations are indicated in Figure 1. Figure S2. Wind roses screening the relative frequencies of occurrence (in percent) of the average 10-min wind (in kt) at different locations of the Madeira Island, in winter. Figure S3. Wind roses screening the relative frequencies of occurrence (in percent) of the wind gust, in summer, at Rosario (top left panel) and at three sites at the Madeira Airport: RWY05 (top right panel), MID (bottom left panel), and RWY23 (bottom right panel). Six wind speed classes (in $\mathrm{kt}$ ) are also shown, as well as the percent of calm $(<5 \mathrm{kt})$ events. Figure S4. Same as figure S3, but for winter (October-March). Figure S5. Wind roses screening the relative frequencies of occurrence (in percent) of the average 2-min wind in winter, at Rosario (top left panel) and at three sites at the Madeira Airport: RWY05 (top right panel), MID (bottom left panel), and RWY23 (bottom right panel). Figure S6. Composites of the daily mean sea level pressure (solid contours) and $700 \mathrm{hPa}$ geopotential height (dashed contours) over the eastern North Atlantic and adjacent landmasses for the outlined weather types (WT) not shown in Figure 5. Figure S7. AROME forecast of the wind gusts at $10 \mathrm{~m}$-height at 03 UTC on 7 August 2016. Figure S8. Time evolution of wind speed, wind gust and wind direction at 10-m height, from AROME forecast and observations at RS site, on 7 August 2016. The time of a missed approach is marked as an impulse (vertical thick line). Figure S9. Same as figure S8, but at RWY23 site. Figure S10. AROME vertical cross-sections of vertical velocity (w) and cross-barrier wind at 15 UTC on 7 august 2016, along A50-A0 (top) and B65-B0 (bottom) lines. Shading represents vertical velocity in $\mathrm{m} \mathrm{s}^{-1}$, positive values indicate upward vertical wind and negative values represent downward vertical wind. The locations of lines A50-A0 and B65-B0 are depicted respectively in Figure 1a,b. Table S1. Relative frequency of each WT during summer (April to September). Percentage of days with daily precipitation above $5 \mathrm{~mm}$ (NR5), $20 \mathrm{~mm}$ (NR20), and $30 \mathrm{~mm}$ (NR30), and the percentage of events with gusts exceeding $30 \mathrm{kt}$ (NG30), $35 \mathrm{kt}$ (NG35), and $40 \mathrm{kt}$ (NG40) in summer, for each weather type, at RWY05. Maximum wind gust (Gust $\mathrm{M}$, in $\mathrm{kt}$ ) and 24-h maximum precipitation (RR) are also indicated. Table S2. Same as Table S1, but for winter (October to March).

Author Contributions: Conceptualization, M.B.-P. and J.A.S.; software, M.B.-P. and J.A.S.; Analysis, M.B.-P. and J.A.S.; writing — original draft preparation, M.B.-P.; writing—review and editing, M.B.-P. and J.A.S.; visualization, M.B.-P. and J.A.S. All authors have read and agreed to the published version of the manuscript.

Funding: FCT_-Portuguese Foundation for Science and Technology, under the project UIDB/04033/2020.

Acknowledgments: The authors are thankful NAV Portugal for providing the wind observations from the Madeira International Airport. The authors thank ANA/Vinci Airports for providing data on the missed approach events. The authors also would like to thank the two anonymous reviewers for their helpful and constructive comments.

Conflicts of Interest: The authors declare no conflict of interest.

\section{Appendix A}

The landing and take-off operations at the Madeira International Airport (MIA) have operating mandatory limitations related to adverse wind conditions, as outlined below:

Wind limitations when landing: 
- In the sector $300^{\circ}$ to $015^{\circ}$ (clockwise), the maximum of two-minutes average wind speed (WS2m) should be inferior to $15 \mathrm{kt}$ and the wind gust should be inferior to $25 \mathrm{kt}$ at the touchdown site. Here, the wind direction refers to the magnetic wind direction.

- In the sector $015^{\circ}$ to $040^{\circ}$ (clockwise) WS2m $<20 \mathrm{kt}$ and maximum wind gust should be inferior to $30 \mathrm{kt}$ at the touchdown site.

- In the sector $120^{\circ}$ to $190^{\circ}$ (clockwise):

$\bigcirc$ if the Runway in use is 05 , WS2 $\mathrm{m}<20 \mathrm{kt}$ and maximum wind gust should be inferior to $30 \mathrm{kt}$;

$\bigcirc$ if the Runway in use is 23, WS2 $\mathrm{m}<15 \mathrm{kt}$ and maximum wind gust should be inferior to $25 \mathrm{kt}$ also at MID.

- In the Sector $200^{\circ}$ to $230^{\circ}$ (clockwise) WS2m and the gust indicated by the MID or RS anemometer should be inferior to $25 \mathrm{kt}$.

Wind limitations when taking-off:

- In the sector $300^{\circ}$ to $015^{\circ}$ (clockwise) WS2m indicated by the MID anemometer should be inferior to $20 \mathrm{kt}$.

- In the sector $015^{\circ}$ to $040^{\circ}$ (clockwise) WS2m indicated by the MID anemometer should be inferior to $25 \mathrm{kt}$.

- In the sector $120^{\circ}$ to $190^{\circ}$ (clockwise):

if the Runway in use is 05 , WS2m indicated by the MID anemometer should be inferior to $25 \mathrm{kt}$;

0 if the Runway in use is 23, WS2m indicated by the MID anemometer should be inferior to $20 \mathrm{kt}$.

\section{References}

1. Mazon, J.; Rojas, J.I.; Lozano, M.; Pino, D.; Prats, X.; Miglietta, M.M. Influence of meteorological phenomena on worldwide aircraft accidents, 1967-2010. Met. Apps. 2018, 25, 236-245. [CrossRef]

2. Gultepe, I.; Sharman, R.; Williams, P.D.; Zhou, B.; Ellrod, G.; Minnis, P.; Trier, S.; Griffin, S.; Yum, S.S.; Gharabaghi, B.; et al. A Review of High Impact Weather for Aviation Meteorology. Pure Appl. Geophys. 2019, 176, 1869-1921. [CrossRef]

3. Clark, T.L.; Hall, W.D.; Kerr, R.M.; Middleton, D.; Radke, L.; Ralph, F.M.; Neiman, P.J.; Levinson, D. Origins of Aircraft-Damaging Clear-Air Turbulence during the 9 December 1992 Colorado Downslope Windstorm: Numerical Simulations and Comparison with Observations. J. Atmos. Sci. 2000, 57, 1105-1131. [CrossRef]

4. Sharman, R.D.; Doyle, J.D.; Shapiro, M.A. An Investigation of a Commercial Aircraft Encounter with Severe Clear-Air Turbulence over Western Greenland. J. Appl. Meteor. Climatol. 2012, 51, 42-53. [CrossRef]

5. Parker, T.J.; Lane, T.P. Trapped Mountain Waves during a Light Aircraft Accident. Aust. Meteorol. Oceanogr. J. 2013, 63, 377-389. [CrossRef]

6. Ágústsson, H.; Ólafsson, H. Simulations of Observed Lee Waves and Rotor Turbulence. Mon. Wea. Rev. 2014, 142, 832-849. [CrossRef]

7. Keller, T.L.; Trier, S.B.; Hall, W.D.; Sharman, R.D.; Xu, M.; Liu, Y. Lee Waves Associated with a Commercial Jetliner Accident at Denver International Airport. J. Appl. Meteorol. Climatol. 2015, 54, 1373-1392. [CrossRef]

8. Maruhashi, J.; Serrão, P.; Belo-Pereira, M. Analysis of Mountain Wave Effects on a Hard Landing Incident in Pico Aerodrome Using the AROME Model and Airborne Observations. Atmosphere 2019, 10, 350. [CrossRef]

9. Smolarkiewicz, P.K.; Rotunno, R. Low Froude Number Flow Past Three-Dimensional Obstacles. Part I: Baroclinically Generated Lee Vortices. J. Atmos. Sci. 1989, 46, 1154-1164. [CrossRef]

10. Schär, C.; Smith, R.B. Shallow-Water Flow past Isolated Topography. Part I: Vorticity Production and Wake Formation. J. Atmos. Sci. 1993, 50, 1373-1400. [CrossRef]

11. Sha, W.; Nakabayashi, K.; Ueda, H. Numerical Study on Flow Pass of a Three-dimensional Obstacle under a Strong Stratification Condition. J. Appl. Meteorol. 1998, 37, 1047-1054. [CrossRef]

12. Jiang, Q.; Smith, R. V-waves, bow shocks, and wakes in supercritical hydrostatic flow. J. Fluid Mech. 2000, 406, 27-53. [CrossRef] 
13. Schär, C.; Durran, D.R. Vortex Formation and Vortex Shedding in Continuously Stratified Flows past Isolated Topography. J. Atmos. Sci. 1997, 54, 534-554. [CrossRef]

14. Epifanio, C.C. Lee Vortices. Encyclopedia of the Atmospheric Sciences; Cambridge University Press: Cambridge, UK, 2014; pp. 1150-1160.

15. Smith, R.B. 100 Years of Progress on Mountain Meteorology Research. Meteorol. Monogr. 2018, 59, 1-73. [CrossRef]

16. Smith, R.B.; Grubišić, V. Aerial Observations of Hawaii's Wake. J. Atmos. Sci. 1993, 50, 3728-3750. [CrossRef]

17. Hubert, L.F.; Krueger, A.F. Satellite pictures of mesoscale eddies. Mon. Wea. Rev. 1962, 90, 457-463. [CrossRef]

18. Chopra, K.P.; Hubert, L.F. Mesoscale Eddies in Wake of Islands. J. Atmos. Sci. 1965, 22, 652-657. [CrossRef]

19. Heinze, R.; Raasch, S.; Etling, D. The Structure of Kármán Vortex Streets in the Atmospheric Boundary Layer derived from Large Eddy Simulation. Meteorol. Z. 2012, 21, 221-237. [CrossRef]

20. Bauer, M.H.; Mayr, G.J.; Vergeiner, I.; Pichler, H. Strongly Nonlinear Flow over and around a Three-Dimensional Mountain as a Function of the Horizontal Aspect Ratio. J. Atmos. Sci. 2000, 57, 3971-3991. [CrossRef]

21. Davis, R.; Hayden, B.; Gay, D.; Phillips, W.L.; Jones, G. The North Atlantic subtropical anticyclone. J. Climate 1997, 10, 728-744. [CrossRef]

22. Carrillo, J.; Guerra, J.C.; Cuevas, E.; Barrancos, J. Characterization of the Marine Boundary Layer and the Trade-Wind Inversion over the Sub-tropical North Atlantic. Bound.-Layer Meteorol. 2016, 158, 311. [CrossRef]

23. Grubišić, V.; Sachsperger, J.; Caldeira, R.M. Atmospheric Wake of Madeira: First Aerial Observations and Numerical Simulations. J. Atmos. Sci. 2015, 72, 4755-4776. [CrossRef]

24. Caldeira, R.M.A.; Tomé, R. Wake Response to an Ocean-Feedback Mechanism: Madeira Island Case Study. Bound. Layer Meteorol. 2013, 148, 419-436. [CrossRef]

25. Couvelard, X.; Caldeira, R.M.A.; Araújo, I.B.; Tomé, R. Wind Meditated Vorticity-generation and Eddy-confinement, Leeward of the Madeira Island: 2008 Numerical Case Study. Dyn. Atmos. Oceans 2012, 58, 128-149. [CrossRef]

26. Santos, J.A.; Belo-Pereira, M.; Fraga, H.; Pinto, J.G. Understanding climate change projections for precipitation over western Europe with a weather typing approach. J. Geophys. Res. Atmos. 2016, 121, 1170-1189. [CrossRef]

27. Dee, D.P.; Uppala, S.M.; Simmons, A.J.; Berrisford, P.; Poli, P.; Kobayashi, S.; Andrae, U.; Balmaseda, M.A.; Balsamo, G.; Bauer, P.; et al. The ERA-Interim reanalysis: Configuration and performance of the data assimilation system. Q. J. R. Meteorol. Soc. 2011, 137, 553-597. [CrossRef]

28. Wilks, D. Statistical Methods in the Atmospheric Sciences; Academic Press: New York, NY, USA, 2011; 704p.

29. Seity, Y.; Brousseau, P.; Malardel, S.; Hello, G.; Bénard, P.; Bouttier, F.; Lac, C.; Masson, V. The AROME-France Convective-Scale Operational Model. Mon. Weather Rev. 2011, 139, 976-991. [CrossRef]

30. Cuxart, J.; Bougeault, P.; Redelsperger, J.-L. A Turbulence Scheme Allowing for Mesoscale and Large-eddy Simulations. Q. J. R. Meteorol. Soc. 2006, 126, 1-30. [CrossRef]

31. Amodei, M.; Sanchez, I.; Stein, J. Verification of the French operational high-resolution model AROME with the regional Brier probability score. Met. Apps. 2015, 22, 731-745. [CrossRef]

32. Alaka, M.A. (Ed.) The Airflow over Mountains; WMO, Technical Note No 98, TP. 34; World Meteorological Organisation: Geneva, Switzerland, 1968; 135p.

33. Vosper, S.B. Inversion Effects on Mountain Lee Waves. Q. J. R. Meteorol. Soc. 2004, 130, 1723-1748. [CrossRef]

34. Mobbs, S.D.; Vosper, S.B.; Sheridan, P.F.; Cardoso, R.; Burton, R.R.; Arnold, S.J.; Hill, M.K.; Horlacher, V.; Gadian, A.M. Observations of downslope winds and rotors in the Falkland Islands. Q. J. R. Meteorol. Soc. 2005, 131, 329-351. [CrossRef]

35. Nína, G.P.; Jón Kristjánsson, E.; Ólafsson, H. The effect of upstream wind direction on atmospheric flow in the vicinity of a large mountain. Q. J. R. Meteorol. Soc. 2005, 131, 1113-1128.

36. ICAO. Annex 3 to the Convention on International Civil Aviation-Meteorological Service for International Air Navigation, 19th ed.; International Civil Aviation Organization (ICAO): Montreal, QC, Canada, 2016; p. 208.

37. Helmis, C.G.; Flocas, H.A.; Kalogiros, J.A.; Asimakopoulos, D.N. Strong downslope winds and application of hydraulic-like theory. J. Geophys. Res. 2000, 105, 18039-18051. [CrossRef]

38. Jiménez, P.A.; Dudhia, J. On the Ability of the WRF Model to Reproduce the Surface Wind Direction over Complex Terrain. J. Appl. Meteorol. Climatol. 2013, 52, 610-1617. [CrossRef]

39. Roeger, C.; Stull, R.; McClung, D.; Hacker, J.; Deng, X.; Modzelewski, H. Verification of Mesoscale Numerical Weather Forecasts in Mountainous Terrain for Application to Avalanche Prediction. Weather Forecast. 2003, 18, 1140-1160. [CrossRef] 
40. Durran, D.R. Another Look at Downslope Windstorms. Part I: The Development of Analogs to Supercritical Flow in an Infinitely Deep, Continuously Stratified Fluid. J. Atmos. Sci. 1986, 43, 2527-2543. [CrossRef]

41. Gaffin, D.M. On High Winds and Foehn Warming Associated with Mountain-Wave Events in the Western Foothills of the Southern Appalachian Mountains. Weather Forecast. 2009, 24, 53-75. [CrossRef]

42. Lane, T.P.; Doyle, J.D.; Sharman, R.D.; Shapiro, M.A.; Watson, C.D. Statistics and Dynamics of Aircraft Encounters of Turbulence over Greenland. Mon. Weather Rev. 2009, 137, 2687-2702. [CrossRef]

43. Guarino, M.; Teixeira, M.A.C.; Keller, T.L.; Sharman, R.D. Mountain-Wave Turbulence in the Presence of Directional Wind Shear over the Rocky Mountains. J. Atmos. Sci. 2018, 75, 1285-1305. [CrossRef]

Publisher's Note: MDPI stays neutral with regard to jurisdictional claims in published maps and institutional affiliations.

(C) 2020 by the authors. Licensee MDPI, Basel, Switzerland. This article is an open access article distributed under the terms and conditions of the Creative Commons Attribution (CC BY) license (http://creativecommons.org/licenses/by/4.0/). 